\title{
Dendrosomatic Sonic Hedgehog Signaling in Hippocampal Neurons Regulates Axon Elongation
}

\author{
Pamela J. Yao, ${ }^{1}$ Ronald S. Petralia, ${ }^{2 \star}$ Carolyn Ott, ${ }^{3 \star}$ Ya-Xian Wang, ${ }^{2}$ Jennifer Lippincott-Schwartz, ${ }^{3}$ \\ and Mark P. Mattson ${ }^{1}$ \\ ${ }^{1}$ Laboratory of Neurosciences, National Institute on Aging-National Institutes of Health, Baltimore, Maryland 21224, ${ }^{2}$ Advanced Imaging Core, National \\ Institute on Deafness and Other Communication Disorders (NIDCD)-National Institutes of Health, Bethesda, Maryland 20892, and ${ }^{3}$ Cell Biology and \\ Metabolism Program, National Institute of Child Health and Human Development-National Institutes of Health, Bethesda, Maryland 20892
}

The presence of Sonic Hedgehog (Shh) and its signaling components in the neurons of the hippocampus raises a question about what role the Shh signaling pathway may play in these neurons. We show here that activation of the Shh signaling pathway stimulates axon elongation in rat hippocampal neurons. This Shh-induced effect depends on the pathway transducer Smoothened (Smo) and the transcription factor Gli1. The axon itself does not respond directly to Shh; instead, the Shh signal transduction originates from the somatodendritic region of the neurons and occurs in neurons with and without detectable primary cilia. Upon Shh stimulation, Smo localization to dendrites increases significantly. Shh pathway activation results in increased levels of profilin1 (Pfn1), an actin-binding protein. Mutations in Pfn1's actin-binding sites or reduction of Pfn 1 eliminate the Shh-induced axon elongation. These findings indicate that Shh can regulate axon growth, which may be critical for development of hippocampal neurons.

Key words: axon; hippocampal neuron; primary cilium; profilin 1; Smoothened; Sonic Hedgehog

\section{Significance Statement}

Although numerous signaling mechanisms have been identified that act directly on axons to regulate their outgrowth, it is not known whether signals transduced in dendrites may also affect axon outgrowth. We describe here a transcellular signaling pathway in embryonic hippocampal neurons in which activation of Sonic Hedgehog (Shh) receptors in dendrites stimulates axon growth. The pathway involves the dendritic-membrane-associated Shh signal transducer Smoothened (Smo) and the transcription factor Gli, which induces the expression of the gene encoding the actin-binding protein profilin 1. Our findings suggest scenarios in which stimulation of Shh in dendrites results in accelerated outgrowth of the axon, which therefore reaches its presumptive postsynaptic target cell more quickly. By this mechanism, Shh may play critical roles in the development of hippocampal neuronal circuits.

\section{Introduction}

Research from the past two decades has shown that the Sonic Hedgehog (Shh) signaling pathway mediates the development

Received April 9, 2015; revised 0ct. 22, 2015; accepted 0ct. 29, 2015.

Author contributions: P.J.Y., R.S.P., C.O., J.L.-S., and M.P.M. designed research; P.J.Y., R.S.P., C.O., and Y.-X.W. performed research; C.O. and J.L.-S. contributed unpublished reagents/analytic tools; P.J.Y., R.S.P., C.O., and M.P.M. analyzed data; P.J.Y. wrote the paper.

This work was supported by the Intramural Research Programs of the National Institute on Aging-National Institutes of Health (NIH), the National Institute on Deafness and Other Communication Disorders (NIDCD)-NIH, and the National Institute of Child Health and Human Development-NIH. The facility code for the Advanced Imaging Core of the NIDCD-NIH is ZIC DC000081-03. We thank Emmette R. Hutchison for assistance with qRT-PCR; Peisu Zhang and Ryan Wu for lentiviral production; Fred E. Indig for confocal imaging; James K. Chen for the Glix8::EGFP construct and Shh-N-expressing HEK 293 cells; James Briscoe for PAP-A and Gli3N constructs; and John Lander for profilin1 constructs.

The authors declare no competing financial interests.

*R.S.P. and C.O. contributed equally to this work.

Correspondence should be addressed to Dr. Pamela J. Yao, Laboratory of Neurosciences, NIA/NIH Biomedical Research Center, 251 Bayview Boulevard, Baltimore, MD 21224. E-mail: yaopa@grc.nia.nih.gov. and maintenance of several different neural circuits in the brain. In the visual system of Drosophila, Hedgehog ( $\mathrm{Hh})$ is produced by photoreceptor neurons and transported along their axons, initiating the differentiation of postsynaptic target cells in the visual processing centers of the brain (Huang and Kunes, 1996; Chu et al., 2006). This presynaptic-to-postsynaptic or, more simply, eyeto-brain, relay of Hh signal determines the highly ordered assembly of neural networks in the Drosophila visual system (Kunes, 2000). In the olfactory system of Drosophila, Hh signaling also plays a role in circuitry development, albeit in a retrograde direction. The axons of olfactory receptor neurons from the periphery respond to and are guided by target-derived Hh from the glomerulus in the brain (Chou et al., 2010). This retrograde Hh signaling process provides the basis for a precise spatial coordination 
between the olfactory receptor neurons in the nose and the glomerular map in the brain (Ressler et al., 1994; Vassar et al., 1994; Vosshall et al., 2000).

In the developing mammalian cerebral cortex, Shh, produced by layer $\mathrm{V}$ corticofugal target neurons, guides network assembly from specific populations of incoming neurons (Harwell et al., 2012). In the adult cortex, Shh signaling is crucial in preserving the nigrostriatal circuit; disruption of Shh signaling from dopaminergic neurons leads to the degeneration of multiple types of neurons in the mesostriatal circuit (Gonzalez-Reyes et al., 2012). Although focusing on different parts of the nervous system and describing a variety of roles, these findings support the conclusion that Shh signaling plays roles in establishing and maintaining the connectivity between neurons.

The neurons in the hippocampus also contain Shh and its key signaling components, including the receptor Patched (Ptch) and the transducer Smoothened (Smo) (Traiffort et al., 1999; Sasaki et al., 2010; Petralia et al., 2011a,b). However, the functions of Shh signaling pathway in hippocampal neurons are unknown. We found previously that Shh pathway activity affects the presynaptic terminals of hippocampal neurons, regulating both their molecular components and function (Mitchell et al., 2012). We now report that, in young hippocampal neurons before they reach the stage of developing synaptic terminals, Shh signaling stimulates axon elongation. Surprisingly, whereas Shh signal transduction initiates from cell bodies and/or dendrites of the neurons, the Shh-induced axon elongation is observed even in neurons that lack detectable primary cilia. Our analysis also shows that the Shh-elicited effect depends on Smo and Gli transcription factors and is mediated through the actin-binding protein profilin1 (Pfn1).

\section{Materials and Methods}

Animals. All animal procedures were approved by the National Institute on Aging-National Institutes of Health (NIH) and the National Institute on Deafness and Other Communication Disorders-NIH Animal Care and Use Committee and complied with the NIH Guide for the Care and Use of Laboratory Animals. Timed pregnant female Sprague Dawley rats were used as the source of embryonic brains to establish cultures of hippocampal neurons.

Reagents. HEK293 cells that overexpress Shh-N were kindly provided by Dr. James K. Chen (Stanford University). We prepared Shh-Nconditioned medium from Shh-N-overexpressing 293 cells exactly as described previously (Chen et al., 2002a,b). The efficacy of ShhN was validated using the Shh-light2 assay (Taipale et al., 2000; Mitchell et al., 2012). Throughout this study, we use $\operatorname{ShhN}$ to refer to Shh-Nconditioned medium. ShhN and control medium were used at $10 \%$ for all experiments. The Shh small-molecule agonist (SAG) and cyclopamine were purchased from Axxora. Robotnikinin was from BioVision. GANT61 and latrunculin A were from Enzo Life Sciences. BDNF was from Cell Sciences. NIH3T3 cells were from the American Type Culture Collection and maintained according to their protocol.

Antibodies. Tuj1 (MMS-435P and MRB-435P) and Smi312 (SMI-312R) antibodies were from Covance. MAP2 antibodies (M1406 and M9942) were from Sigma-Aldrich. ACIII (adenylate cyclase III) antibody (sc-588) was from Santa Cruz Biotechnology. Acetylated tubulin (T6793) and $\beta$-actin (A5441) antibodies were from Sigma-Aldrich. RPCA-ACIII antibody was from EnCor Biotechnology. Arl13b antibody (75-287) was from NeuroMab. Smo antibody (ab38686) was from Abcam. Antibodies to Gli1 (2534), Profilin1 (3237), cofilin (5175), and phosphor-cofilin (3313) were from Cell Signaling Technology. Profilin2a antibody (PF2A3) was from the Developmental Studies Hybridoma Bank.

DNA and shRNA constructs. The Shh activity reporter Glix8::EGFP was kindly provided by Dr. James K. Chen at Stanford University (Hyman et al., 2009). The Gli repressor constructs Gli3N and PAP-A were kindly provided by Dr. James Briscoe at the Medical Research Council National
Institute for Medical Research (London). All profilin1 constructs were kindly provided by Dr. John E. Landers at the University of Massachusetts Medical School (Wu et al., 2012).

The rat profilin1 pGIPZ-shRNA clones were obtained from GE Healthcare/Dharmacon. Among the four candidate shRNAs, the clone V3LHS_366349 (5'-CTTGTTGATCAAACCACCG-3') was the most consistent and effective in reducing profilin 1 protein abundance of both neurons (see Fig. 8A,B) and NIH 3T3 cells (P.J.Y., unpublished findings). Lentiviral shRNAs were produced using the method described by Salmon and Trono (2007).

The Smo shRNA was designed exactly as described by Parra and Zou (2010) and the construct pRFP-CB-shLenti-Smo-shRNA was produced by OriGene (clone HT 138738A; the identical clone used by Parra and Zou, 2010). The efficacy of the Smo shRNA in reducing Smo in hippocampal neurons was confirmed (see Fig. $2 G$ ).

Hippocampal neuron culture and transfection. Cultures of hippocampal neurons were prepared from embryonic day 18 rat brains as described previously (Mattson et al., 1989; Kaech and Banker, 2006; Bushlin et al., 2008). Dissociated neurons were plated at low density ( $\sim 50-100$ cells $\left.\mathrm{mm}^{-2}\right)$ for immunofluorescence and at high density $\left(\sim 200\right.$ cells $\left.\mathrm{mm}^{-2}\right)$ for transfection, immunoblotting, and live-cell imaging experiments. The neurons were grown in neurobasal medium supplemented with B27 (Invitrogen). For immunofluorescence and live-cell imaging, the neurons were grown on polylysine $\left(1 \mathrm{mg} \mathrm{ml}^{-1}\right)$-coated glass coverslips (thickness \#1.5). For immunoblotting, the neurons were grown in polylysine-coated plastic dishes. The age of the cultures used for each experiment is indicated in the figure legends. For transfection experiments, a calcium-phosphate-based kit (Invitrogen) was used.

For compartmentalized cultures, dissociated neurons were plated and grown in microfluidic chamber devices (Xona Microfluidics) following a protocol described by Taylor et al. (2005) and Park et al. (2006). Neurons were grown for at least $2 \mathrm{~d}$ to allow axons to enter into microchannels. Total volume difference between the two compartments was kept at $50 \mu \mathrm{l}$ to maintain fluidic isolation during experiments.

Immunocytochemistry, fluorescence microscopy, and image analysis. Immunofluorescence labeling was performed as described previously (Bushlin et al., 2008). In brief, neurons were fixed in $4 \%$ paraformaldehyde and $4 \%$ sucrose for $15 \mathrm{~min}$, permeabilized in $0.2 \%$ Triton X-100, and blocked in $10 \%$ BSA. The neurons were then incubated with a primary antibody overnight at $4^{\circ} \mathrm{C}$. The dilutions of the primary antibodies used in this study were as follows: Tuj1, 1:1000; Smi312, 1:1000; MAP2, 1:2500; and ACIII, 1:500. After washing, the neurons were incubated with an appropriate fluorescently tagged secondary antibody. The glass coverslips containing the labeled neurons were mounted in Prolong antifade reagent (Life Technologies).

The labeled neurons were examined using a $40 \times$ or a $63 \times$ objective on a Zeiss LSM710 laser scanning confocal microscope. All images were acquired at a $1024 \times 1024$ pixel resolution. The confocal acquisition settings were kept the same for those samples when quantification was performed. The brightness, contrast, and levels of the images were minimally adjusted (in Adobe Photoshop CS6) for those images presented. No additional digital image processing was performed.

Two or three coverslips from each culture were used for analysis. In each coverslip, the first $\sim 10$ neurons with clearly traceable axons and dendrites were photographed. Axons were identified based on positive immunolabeling for Smi312 and Tuj1. The length of axons and dendrites was measured using ImageJ.

For measuring axon growth in compartmentalized cultures, we used two methods. For neurons at $3 \mathrm{~d}$ in culture, we traced individual axon bundles from soma barrier to axon tips and measured their length. For neurons at $5 \mathrm{~d}$ in culture or older, we measured mean fluorescence intensity of Smi312- or Tuj1-labeled axons in a defined area from soma barrier to axon tips.

Live-cell imaging and kymograph analysis. Live-cell imaging experiments were performed using a Zeiss LSM780 laser scanning confocal microscope outfitted with a sealed environmental chamber that was set at $37^{\circ} \mathrm{C}$ and $5 \%$ $\mathrm{CO}_{2}$. We selected neurons with these two criteria for imaging: (1) exhibited unambiguous neuronal morphology and (2) expressed a low to moderate level of Smo::tdTomato. We distinguished axons from dendrites based on 
A

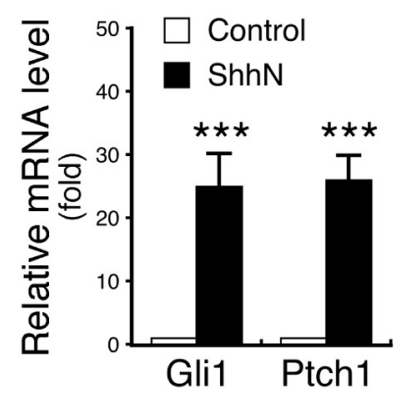

B

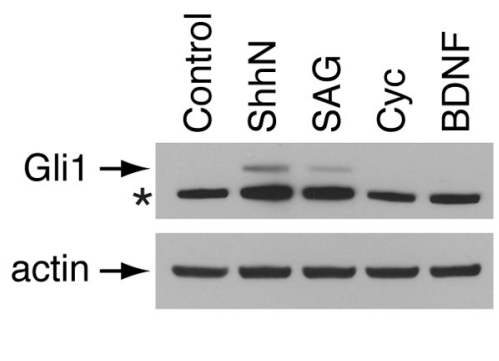

C

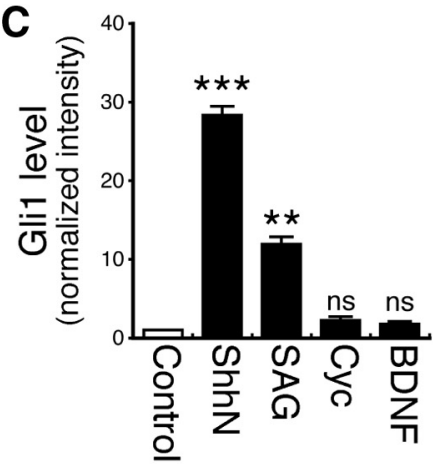

D

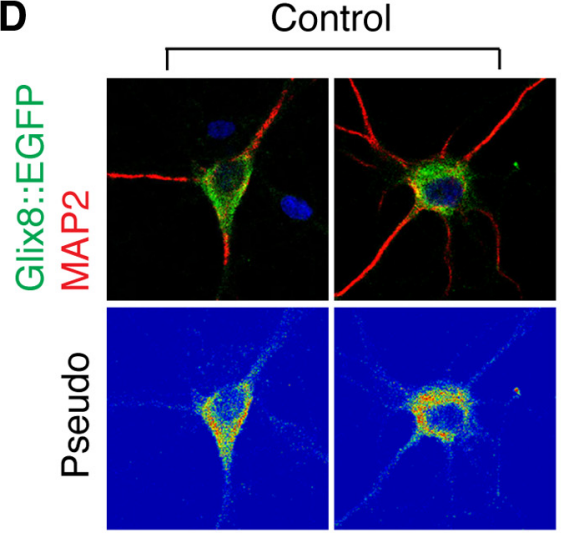

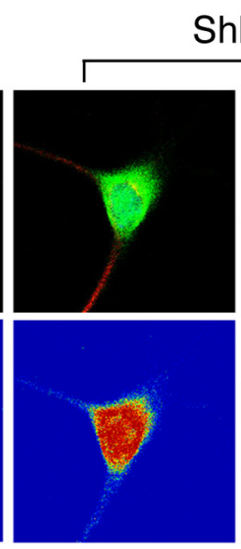

ShhN

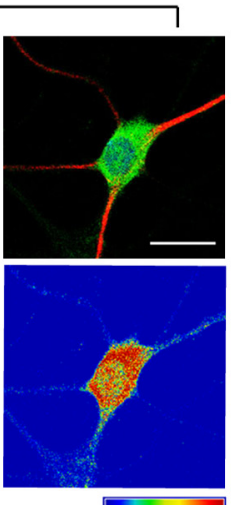

$\mathbf{E}$

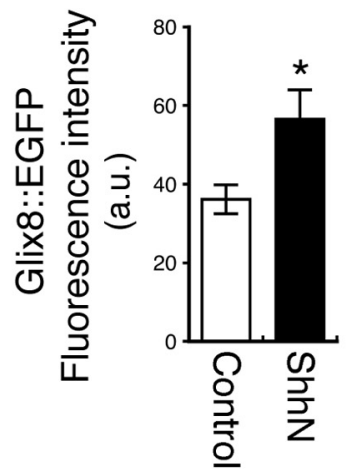

Figure 1. The Shh signaling pathway can be activated in hippocampal neurons. Hippocampal neurons were treated with ShhN for 1 or 2 d. A, qRT-PCR analysis of ShhN-treated neurons shows robustly elevated expression of Gli1 and Ptch1 mRNA compared with neurons in control cultures ( $n=4$ for Gli1; $n=3$ for Ptch1. $n=$ the number of biological replicates; cultures established from embryos from different timed-pregnant rats). $\boldsymbol{B}$, Immunoblot showing increased Gli1 protein level in neurons treated with ShhN or SAG (400 nm), but not in neurons treated with cyclopamine (Cyc, $10 \mu \mathrm{M}$ ) or BDNF (50 $\mathrm{ng} / \mathrm{ml})$. * Nonspecific band. C, Quantification of $\boldsymbol{B} . n=3 . \mathbf{D}$, Images on the top show neurons that were transfected with Glix8::EGFP (green), a reporter for Shh signaling activity, followed by labeling with a neuronal marker MAP2 (red). Images on the bottom show relative levels of Glix8::EGFP fluorescence on a pseudocolor scale. Notice increased Glix8::EGFP expression in ShhN-treated neurons. Scale bar, $20 \mu \mathrm{m}$. E, Glix8::EGFP fluorescence intensity in the cell body area was quantified. $n=15$ cells for each. Error bars indicate SEM. ${ }^{* * *} p<0.001,{ }^{* *} p<0.01,{ }^{*} p<$ 0.05 , unpaired $t$ test. ns, Not significant.

their morphological characteristics (Banker and Goslin, 1988; Mattson et al., 1989; Bushlin et al., 2008). Image acquisition was performed every 200-250 $\mathrm{ms}$ for a total of 200 frames. The frame size was minimized to cover only the portion of the dendrite being imaged. Kymographs were generated using Image J and the velocity of Smo particles was analyzed as described previously (Ott and Lippincott-Schwartz, 2012).

Immunoelectron microscopy. Postembedding immunogold labeling was performed following established methods (Petralia and Wenthold, 1999; Bushlin et al., 2008; Petralia et al., 2010). Briefly, after cryoprotection and embedding, tissue sections were further processed and embedded in Lowicryl HM-20 resin using a Leica AFS freeze-substitution instrument. After blocking, sections were incubated with primary antibody. Smo antibody was used at 1:100. After incubation with $10 \mathrm{~nm}$ gold-conjugated secondary antibody, the sections were stained with uranyl acetate and lead citrate.

For all electron microscopy methods, images were stored in their original formats and final images for figures were prepared in Adobe Photoshop; levels and brightness/contrast of images were minimally and evenly adjusted over the entire micrograph. Control sections omitting the primary antibody showed only rare gold labeling.

$q R T-P C R$. Total RNA was isolated from neurons using TRIzol (Invitrogen). One microgram of RNA was reverse transcribed with random hexamers using SuperScript III reverse transcriptase (Invitrogen). The resulting cDNA (1/10) was used as a template for qRT-PCR with SYBR Green Master Mix (Invitrogen) on an MJ Research PTC-200 thermocycler. Sequences were as follows: Gli1, 5'-ATGGATACTAGAGGGCTACAGG-3', and Ptch1, 5'-GGTTGTGGGTCTCCTCATATTT-3'.
Immunoblot analysis. Cells were lysed in RIPA buffer $(20 \mathrm{~mm}$ Tris- $\mathrm{HCl}$, $150 \mathrm{~mm} \mathrm{NaCl}, 1 \mathrm{~mm}$ EDTA, $1 \mathrm{~mm}$ EGTA, 1\% NP-40, 2.5 mm sodium pyrophosphate, $1 \mathrm{~mm}$ sodium orthovanadate, and $1 \%$ sodium deoxycholate) containing protease inhibitors. The lysed cells were centrifuged at $10,000 \times \mathrm{g}$ for $10 \mathrm{~min}$ at $4^{\circ} \mathrm{C}$. The amount of total proteins in the cell lysates was estimated with a Pierce BCA protein assay kit. Protein samples were separated by $4-20 \%$ Bis-Tris SDS-PAGE and transferred to nitrocellulose membranes. After incubation with blocking buffer (5\% dry milk and $0.05 \%$ Tween 20 in PBS), the membranes were incubated overnight at $4^{\circ} \mathrm{C}$ in the blocking buffer containing the following antibodies: Gli1, 1:1000; Pfn1, 1:1000; Pfn2a, 1:200; cofilin, 1:1000; phos-cofilin, 1:1000; and $\beta$-actin, 1:5000. The membranes were then washed $(0.1 \%$ Tween 20 in PBS) and incubated with the appropriate peroxidaseconjugated secondary antibodies. The proteins were visualized using a chemiluminescence kit from Pierce. The intensity of protein bands was analyzed using ImageJ software.

Data analysis and statistics. Statistical comparisons were performed using Student's $t$ test (KaleidaGraph software; Synergy). All results are expressed as mean $\pm \mathrm{SEM}$.

\section{Results}

Activation of the Shh signaling pathway in hippocampal neurons

To determine whether young hippocampal neurons respond to Shh, we treated the neurons with ShhN for 1-2 d and then measured the expression levels of Gli1 and Ptch1. Gli1 and Ptch1 are 
A
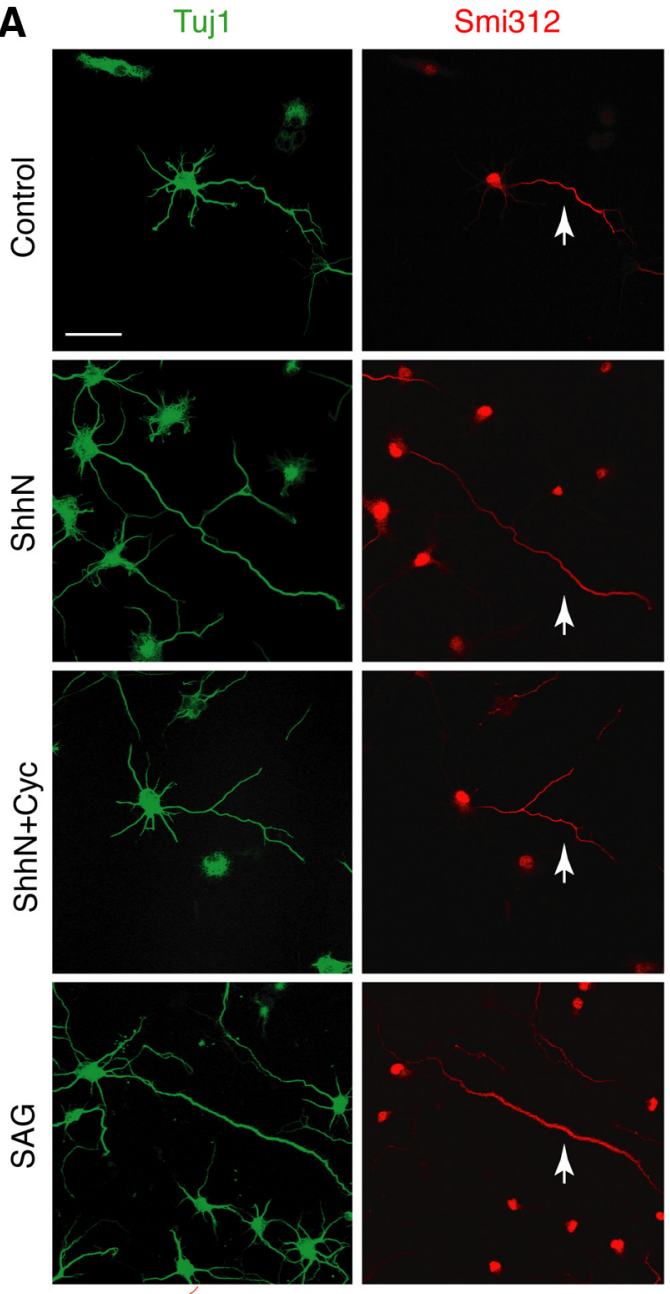

E

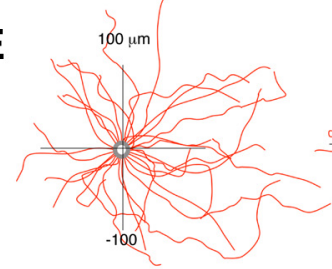

Ctr-shRNA/ShhN

F

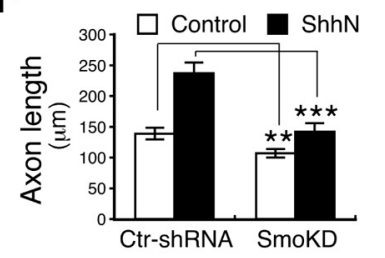

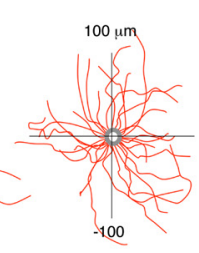

Smo-shRNA/ShhN

\section{G}

anti-Smo/ Smo-shRNA

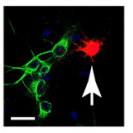

H $ح 100 \mu \mathrm{m}$

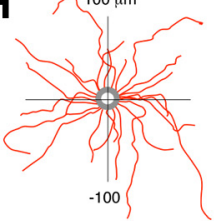

Control/Vehicle

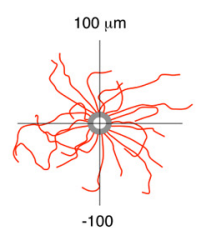

Control/GANT61 merge
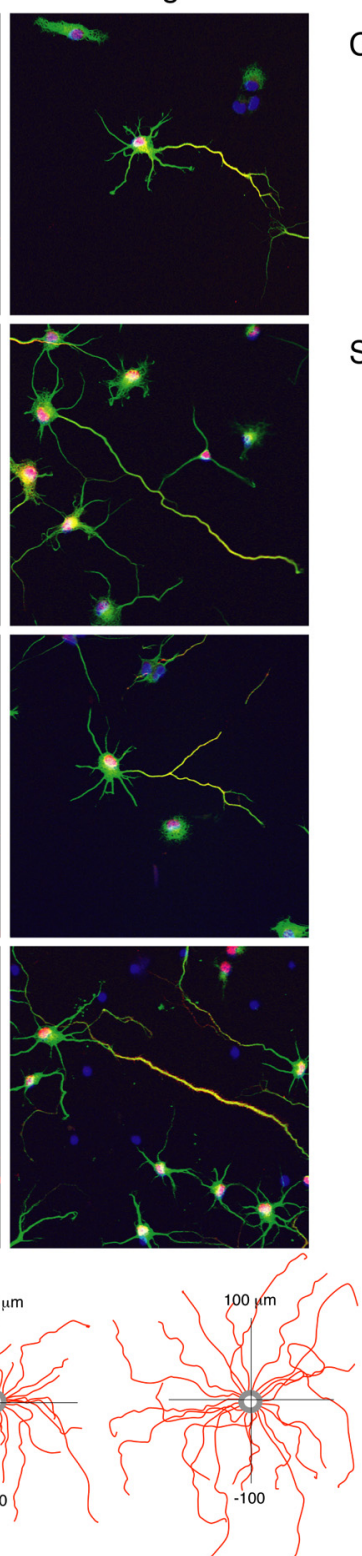

ShhN/Vehicle

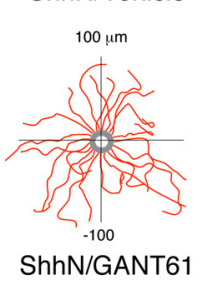

B

Control

C
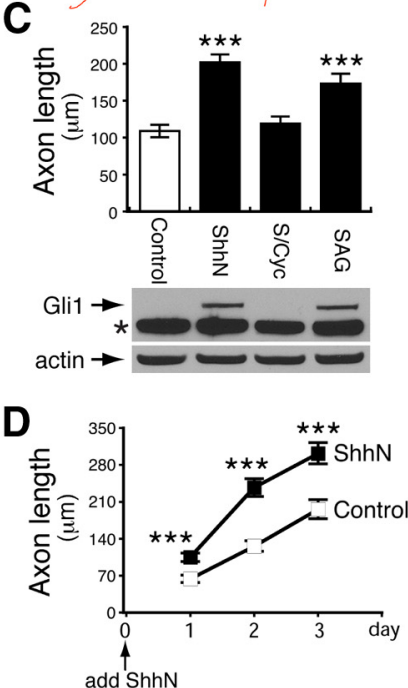

I

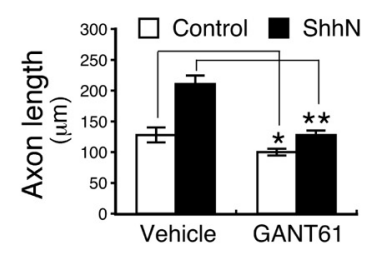

J

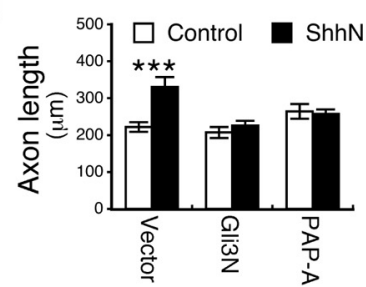

Figure 2. Shh promotes axon elongation in young hippocampal neurons. $\boldsymbol{A}$, Fluorescent images of hippocampal neurons treated with $S h h N$ alone, or ShhN plus cyclopamine (10 $\mu \mathrm{m}$ ), or $S A G$ alone $(400 \mathrm{~nm})$ for $2 \mathrm{~d}$. Tuj1 (green) is a neuronal marker; Smi312 (red) is an axonal marker. Arrows point to axons. Scale bar, $20 \mu \mathrm{m}$. $\boldsymbol{B}$, Compiled traces of axons from randomly sampled neurons from three different cultures. C, Top, Quantification of axon length. $n>60$ neurons from at least six cultures. S/Cyc, ShhN plus cyclopamine (10 $\mu$ m). Bottom, Immunoblot analysis from parallel experiments showing that conditions that increase axon length also elevate Gli1 protein levels. $\boldsymbol{D}$, Time course experiments. $n>40$ neurons from three to six cultures. $\boldsymbol{E}$, Compiled traces of axons from neurons expressing either a control shRNA construct (Ctr-shRNA) or a Smo-shRNA construct. $\boldsymbol{F}$, Bar graph showing that Smo knock-down (SmoKD) resulted in shorter axons in both control and ShhN-treated groups. $n \geq 30$ neurons from three cultures. G, Fluorescent image of hippocampal neurons immunolabeled with a Smo antibody (green). Arrow points to a neuron expressing Smo-shRNA-RFP (red). Scale bar, $20 \mu \mathrm{m}$. $\boldsymbol{H}$, Compiled traces of axons from representative neurons treated with ShhN in the absence or presence of the Gli1 inhibitor GANT61 (10 $\mu \mathrm{M}$ ). I, Quantification of the axon length for the GANT61 experiments. $n=30$ neurons from three cultures. J, Quantification of the axon length from neurons transfected with a control vector or with Gli repressors (Gli3N or PAP-A) and treated with ShhN. Both Gli3N and PAP-A block the ShhN-induced axon elongation. $n>30$ neurons from three to five cultures. Error bars indicate SEM. ${ }^{* *} p<0.001,{ }^{* *} p<0.01,{ }^{*} p<0.05$, unpaired $t$ test. 
A

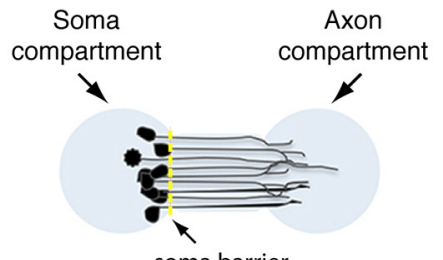

c
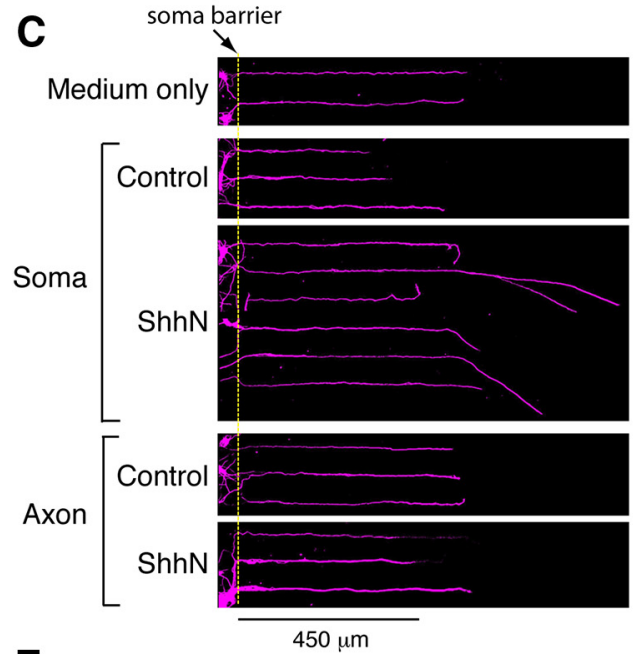

E

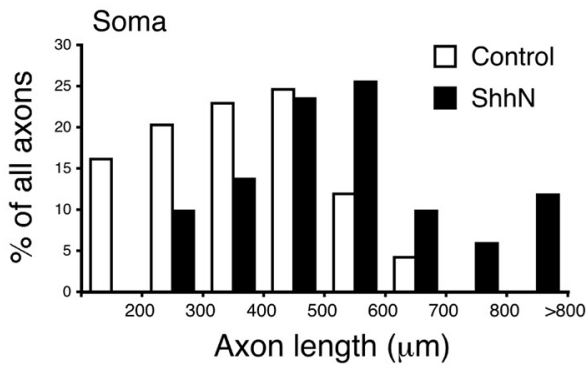

G

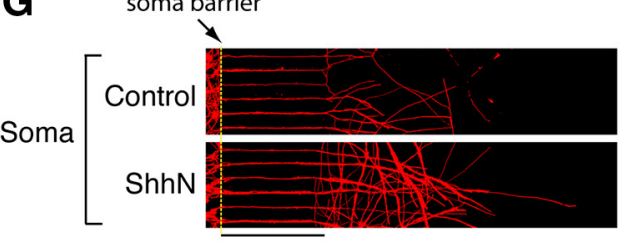

I

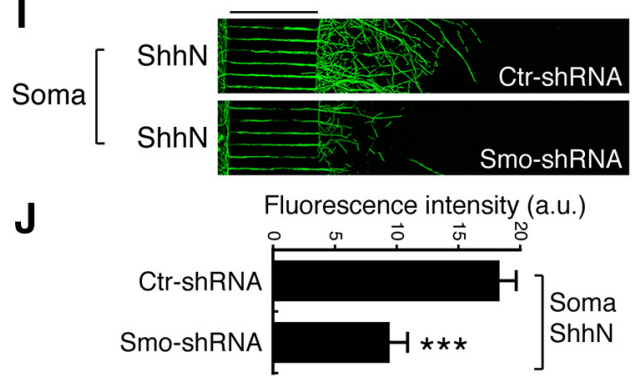

B

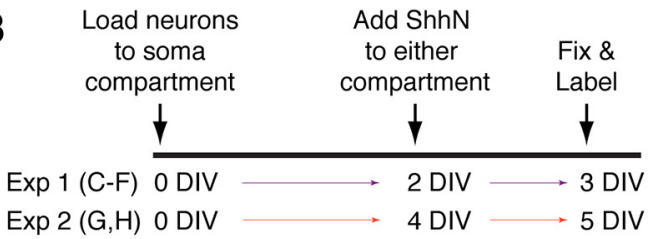

D

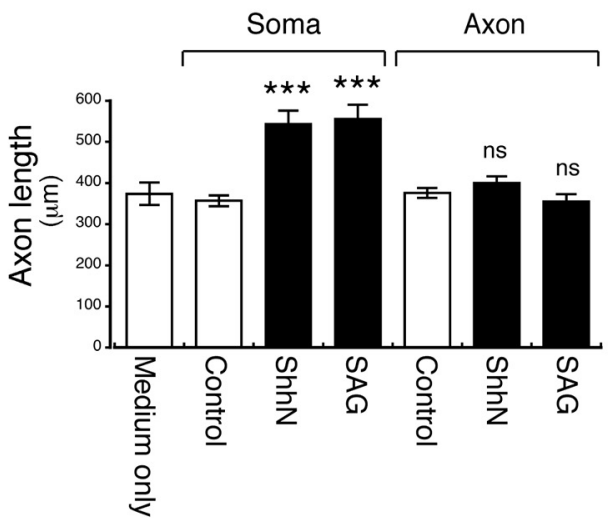

F

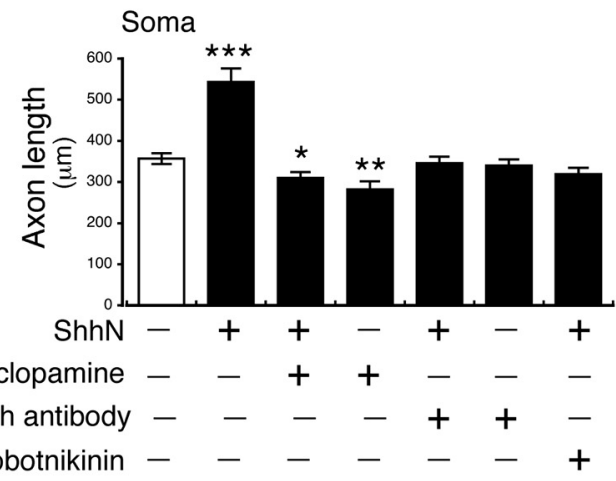

H

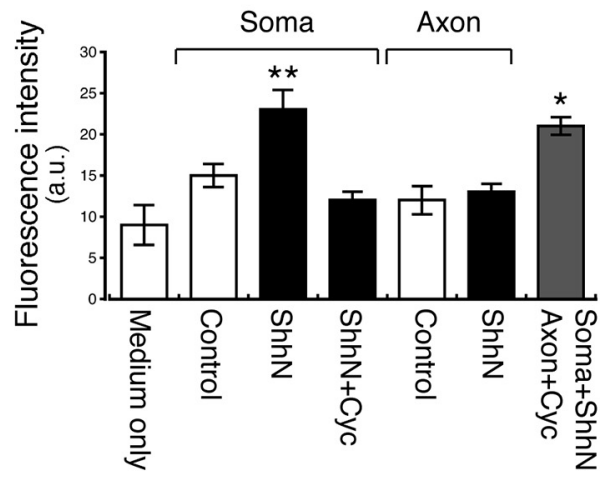

Figure 3. Shh signaling is initiated in the dendrites/cell body and not in the axon. $\boldsymbol{A}$, Schematic representation of the compartmentalized system. $\boldsymbol{B}$, Experimental timeline. In Experiment 1 (Exp 1), neurons were grown in the compartmentalized system for $2 \mathrm{~d}(2 \mathrm{DIV})$ before treatment with ShhN for $24 \mathrm{~h}(\boldsymbol{C}-\boldsymbol{F})$. In Exp 2, neurons were grown for $4 \mathrm{~d}$ before treatment with ShhN for $24 \mathrm{~h}(\mathbf{G}$, $\boldsymbol{H})$. $($, Representative images of axons growing through the microtunnels into the axon compartment. Many neurons grew longer axons when ShhN was added exclusively to the somatodendritic compartment. $\boldsymbol{D}$, Quantitative analysis of axon lengths of neurons exposed to the indicated treatments that were applied either to the somatodendritic or axon compartments. Individual axons were traced and measured from soma barrier (yellow dashed line in $\boldsymbol{C}$ ) to axon tips. $n=$ at least 60 axons obtained from five or six cultures. $E$, Distribution of axon lengths of neurons to which ShhN was applied to the somatodendritic compartment. $\boldsymbol{F}$, Quantitative analysis of axon lengths of neurons exposed to the indicated treatments that were applied (Figure legend continues.) 
strongly induced by Shh signaling, so their expression levels serve as sensitive and reliable readouts of the pathway activity (Ingham and McMahon, 2001; Varjosalo and Taipale, 2008). Assessment of the mRNA by qRT-PCR of ShhN-treated neurons showed a robust increase of Gli1 and Ptch1 mRNA, 20-fold more than untreated control neurons (Fig. 1A). Immunoblot analysis of total cellular proteins showed that ShhN or small-molecule agonist (SAG) (400 nM) increased Glil protein abundance, whereas cyclopamine (a Shh antagonist; $10 \mu \mathrm{M}$ ) or BDNF (50 ng/ml) did not (Fig. $1 B, C$ ). ShhN treatment also increases protein abundance for Ptch1 (Mitchell et al., 2012) and Neuropilin1 (P.J.Y., unpublished observations), a protein known to be upregulated by Shh signaling activity (Hillman et al., 2011).

To evaluate the response of individual neurons to Shh treatment, we transfected neurons with Glix8::EGFP, a Shh pathway reporter (Hyman et al., 2009) that expresses EGFP under the control of a Gli1-responsive promoter. In untreated control neurons, we observed low but detectable expression of Glix8::EGFP, possibly reflecting endogenous constitutive Shh pathway activity in these neurons (Fig. 1D, left). After ShhN treatment, the expression of Glix8::EGFP was visibly increased (Fig. $1 D$, right, Fig. $1 E$ ). Therefore, exogenously provided ShhN induces Shh pathway activity in young hippocampal neurons.

\section{Shh promotes axon elongation in hippocampal neurons}

To determine the effect of ShhN treatment on the growth of young hippocampal neurons, we added ShhN to neurons on the day of plating ( $0 \mathrm{~d}$ in vitro, DIV) and examined the neurons $2 \mathrm{~d}$ later $(0+2 \mathrm{DIV})$. To visualize neurons and identify their axons, we labeled cells with the neuronal marker Tuj1 and the axonal marker Smi312 (Fig. 2A). ShhN treatment did not appear to affect the number of neurites per neuron or the proportion of neurons that developed an axon (P.J.Y., unpublished observations); however, many axons from ShhN-treated neurons were noticeably longer (Fig. 2A,B). The average axon length for untreated control neurons at $2 \mathrm{DIV}$ was $\sim 100 \mu \mathrm{m}$, whereas the length of the axons from ShhN-treated neurons nearly doubled $(109 \pm 8.3 \mu \mathrm{m}$ vs $202 \pm 10.6 \mu \mathrm{m}, p<0.001 ; n>60$ neurons from at least 6 cultures; Fig. 2C). This Shh-induced axon elongation was also observed in neurons treated with ShhN for either 1 or $3 \mathrm{~d}$ (Fig. 2D).

The axon elongation phenotype was also evident in neurons treated with SAG. However, cotreatment of ShhN and the antagonist cyclopamine blocked ShhN's stimulative effect (Fig. 2A,C). Because both SAG and cyclopamine target Smo directly (Taipale et al., 2000; Chen et al., 2002a,b), these data suggest that the observed ShhN-induced axon elongation is likely mediated through Smo. To confirm this, we tested a Smo-shRNA construct

\footnotetext{
$\leftarrow$

(Figure legend continued.) to the somatodendritic compartment. Cyclopamine, $10 \mu \mathrm{m}$; Shh antibody, 1:100; Robotnikinin, $50 \mu \mathrm{M}$. G, Representative images of axons from neurons grown in the compartmentalized system for $4 \mathrm{~d}$ and then exposed to ShhN that was applied to the somatodendritic compartment. Neurons were labeled with Tuj1 (red). Scale bar, $450 \mu \mathrm{m}$. $\boldsymbol{H}$, Quantitative analysis of axons as measured by Tuj1 immunofluorescence intensity in neurons exposed to the indicated treatments that were applied either to the somatodendritic or axon compartments. Notice that cyclopamine (10 $\mu \mathrm{m})$ blocked ShhN's effect only when it was added to the somatodendritic compartment. $n=4$ cultures. I, Representative images of Tuj1 (green) labeled hippocampal neurons infected with either the control or Smo shRNA lentivirus. ShhN was added to the somatodendritic compartment. Scale bar, $450 \mu \mathrm{m}$. J, Comparison of axon density as measured by Tuj1 immunolabeling intensity between hippocampal neurons expressing either control or Smo shRNA. $n=4$. Error bars indicate SEM. ${ }^{*} p<0.05,{ }^{* *} p<0.01$, ${ }^{* * *} p<0.001$, unpaired $t$ test. ns, Not significant.
}

that effectively reduced Smo protein level in rat spinal cord commissural axons (Parra and Zou, 2010) and hippocampal neurons (Fig. 2G). Figure 2, $E$ and $F$, shows that knock-down of Smo largely prevented ShhN-elicited axon elongation. Furthermore, in the neurons without ShhN treatment, knock-down of Smo caused them to grow subtly but significantly shorter axons (SmoshRNA $107 \pm 7.4 \mu \mathrm{m}$ vs Ctr-shRNA $129 \pm 9.3 \mu \mathrm{m} p<0.01 ; n \geq$ 30 neurons from 3 cultures; Fig. $2 F$ ), implying that the endogenous Smo-mediated Shh pathway activity contributes to axon growth in hippocampal neurons.

We next investigated whether the Shh-induced axon growth depended on Gli-mediated transcription. We used the Gli inhibitor GANT61 (Lauth et al., 2007). Cotreatment of ShhN with GANT61 $(10 \mu \mathrm{M})$ completely abolished axon elongation induced by ShhN (Fig. $2 H, I$ ), suggesting that ShhN-induced axon elongation is mediated by transcriptional targets of Gli. When neurons were treated with GANT61 alone without exogenously added ShhN, their axons were shorter than the axons from untreated control (GANT61 treated $100 \pm 5.5 \mu \mathrm{m}$ vs untreated control $128 \pm 7.4 \mu \mathrm{m}, p<0.05$; Fig. $2 H, I)$. This result, together with the observed reporter expression in control cells (Fig. $1 D, E$ ) and Smo shRNA result (Fig. $2 F$ ), suggests that, in control neurons, endogenous Smo- and Gli-dependent Shh pathway activity could contribute to the basal rate of axon growth. We also tested the effect of the Gli3 repressor constructs Gli3N and PAP-A (Briscoe and Therond, 2013). The expression of either construct in neurons blocked ShhN-induced axon elongation (Fig. 2J; vector/ ShhN $330 \pm 27 \mu \mathrm{m}$ vs vector/control $222 \pm 13 \mu \mathrm{m}$, Gli3N/ShhN $226 \pm 15 \mu \mathrm{m}$, and PAP-A/ShhN $257 \pm 13 \mu \mathrm{m} ; n>50$ axons from 3-5 cultures).

It has been reported that Shh affects dendritic spines of older mature neurons (Sasaki et al., 2010). However, in young neurons at the early developmental stage that we studied, we did not observe any evident changes in dendrite length after either ShhN or SAG treatment (control $82 \pm 16 \mu \mathrm{m}$ vs ShhN $117 \pm 27 \mu \mathrm{m}, p>0.05$; control $82 \pm 16 \mu \mathrm{m}$ vs SAG $108 \pm 24 \mu \mathrm{m}, p>0.05)$. Therefore, we focused on Shh's effect on axon growth in this study.

\section{Shh signaling initiates at the somatodendritic sites}

To determine where in the hippocampal neuron Shh signal transduction might initiate, we used a compartmentalized microfluidic culture system that allowed us to treat the cell bodies and dendrites or the distal axons exclusively (Taylor et al., 2005; Park et al., 2006). The fluids on each side of the chamber are isolated due to the long $(450 \mu \mathrm{m})$ and narrow channels and the difference in fluid volume. Hippocampal neurons loaded into one side of the microfluidic device typically extend their axons into and through microchannels after $2 \mathrm{~d}$ in culture (Fig. $3 A$ ). Dendrites from hippocampal neurons as old as 10 DIV are not long enough to traverse the $450 \mu \mathrm{m}$ channels (Taylor et al., 2005; Park et al., 2006; Taylor et al., 2010; and P.J.Y., unpublished observations). Therefore, we used the device with $450 \mu \mathrm{m}$ channels in our experiments and refer to the two compartments as the somatodendritic compartment and axon compartment.

We first examined neurons that were grown in the compartmentalization device for $2 \mathrm{~d}$, followed by treatment with ShhN for $1 \mathrm{~d}$ (Fig. $3 B$ ). When ShhN or SAG was added to the axon compartment, we did not observe any differences in axon length compared with the control (Fig. 3C,D). However, when ShhN or SAG was added to the somatodendritic compartment, many axons became significantly longer (Fig. $3 C, D$ ). The population analysis showed that the axon length distribution shifted upon somatodendritic treatment with ShhN (Fig. 3E). We conclude 
that the observed ShhN-induced effect of axon elongation was a direct result of ShhN activity because it was blocked by coapplying to the somatodendritic compartment ShhN and either a Shh-specific antibody or the Shh blocker robotnikinin (50 $\mu \mathrm{M}$; Stanton et al., 2009) (Fig. 3F).

Cyclopamine applied to the somatodendritic compartment not only blocked the ShhN-induced effect, but also resulted in slightly shorter (statistically significant) axons than measured in untreated control neurons (untreated control $357 \pm 13 \mu \mathrm{m}$ vs cyclopamine/ShhN $310 \pm 14 \mu \mathrm{m}, p<$ 0.05; Fig. $3 F)$. Like the Gli inhibitor GANT61, cyclopamine treatment without ShhN resulted in reduced axon growth (untreated control $357 \pm 13 \mu \mathrm{m}$ vs cyclopamine $282 \pm 20 \mu \mathrm{m}, p<0.01)$. Therefore, it appears that Shh pathway activity in the cell body or dendrites contributes to axon growth in the primary culture system.

We repeated the experiments using older neurons (Fig. 3B). Although tracing individual axons was no longer reliable in older neurons (Fig. 3G), we could quantify axon density based on areal changes in immunofluorescence intensity of the Tuj1-labeled axons. We observed significantly increased axon density only when ShhN was applied to the somatodendritic compartment, not when it was added to the axons of the neurons (Fig. $3 G, H$ ). The blocking effect of cyclopamine was again observed only when it was added to the somatodendritic side of the neurons. Furthermore, we infected neurons with a lentiviral construct that harbored the Smo shRNA (Fig. 2G). We found that the axon length and density of ShhN-treated, Smo shRNA-infected neurons were significantly less than those of the axons of ShhN-treated, control shRNA-infected neurons, as deduced from fluorescence intensity of the Tuj1-immunolabeled axons (Fig. 3I,J). Together, these findings suggest that, in developing hippocampal neurons, Shh signaling begins from the cell bodies/dendrites, is mediated through Smo and Gli, and stimulates axon outgrowth.

Shh-induced axon elongation occurs in neurons that contain or lack the primary cilium

The primary cilium, a small membranous protrusion (Ott et al., 2012; Beales and Jackson, 2012 and references within), plays a central role in Shh signaling (Huangfu et al., 2003; Louvi and Grove, 2011). Because all mammalian Shh signaling is thought to occur through cilia-
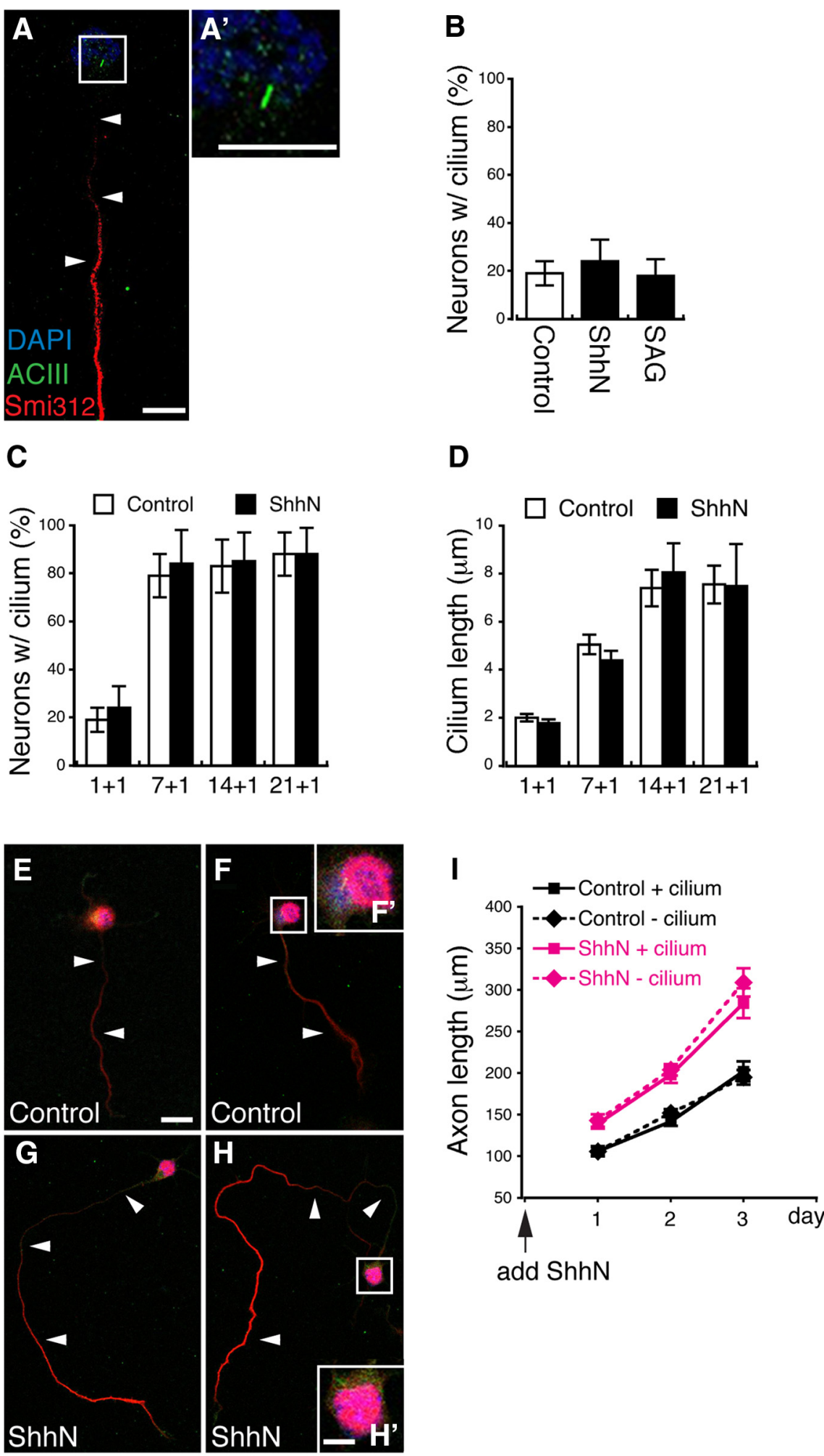

Figure 4. Shh-induced axon elongation occurs in neurons that lack or contain a primary cilium. $\boldsymbol{A}$, Image of a hippocampal neuron (2 DIV) immunolabeled with antibodies against Smi312 (red; axonal marker) and ACIII (green; cilia marker). Arrowheads point to the axon including the initial segment of the axon that is weakly labeled by Smi312. $\boldsymbol{A}^{\prime}$ is an enlarged view of the boxed area in $\boldsymbol{A}$. Scale bars, $10 \mu \mathrm{m}$. $\boldsymbol{B}$, Number of young neurons (1 DIV $+1 \mathrm{~d}$ treatment) that contain the ACIII-immunolabeled primary cilia is not affected by ShhN or SAG $(400 \mathrm{~nm}) . n=45$ neurons from three cultures. $C$, Number of cilium-containing neurons increases as neurons mature in culture $(1+1=$ 1 DIV $+1 \mathrm{~d}$ treatment; $7+1=7$ DIV $+1 \mathrm{~d}$ treatment; and so forth) and is unaffected by ShhN. $\boldsymbol{D}$, Length of the primary cilium also increases as neurons mature. ShhN treatment does not affect the cilium length. $\boldsymbol{E}-\boldsymbol{H}$, Examples of neurons without a cilium $(\boldsymbol{E}, \boldsymbol{G})$ and neurons with a cilium ( $\boldsymbol{F}$ and inserts in $\boldsymbol{F}^{\prime}, \boldsymbol{H}_{,} \boldsymbol{H}^{\prime}$ ). Neurons were labeled with Smi-312 (red) and ACIII (green). White arrowheads point to the axons. Scale bars, $10 \mu \mathrm{m}$. I, Quantitative analysis showing that ShhN-induced axon elongation is similar in neurons with a primary cilium and neurons without a primary cilium. $n=40-60$ neurons from four cultures. Error bars indicate SEM. 

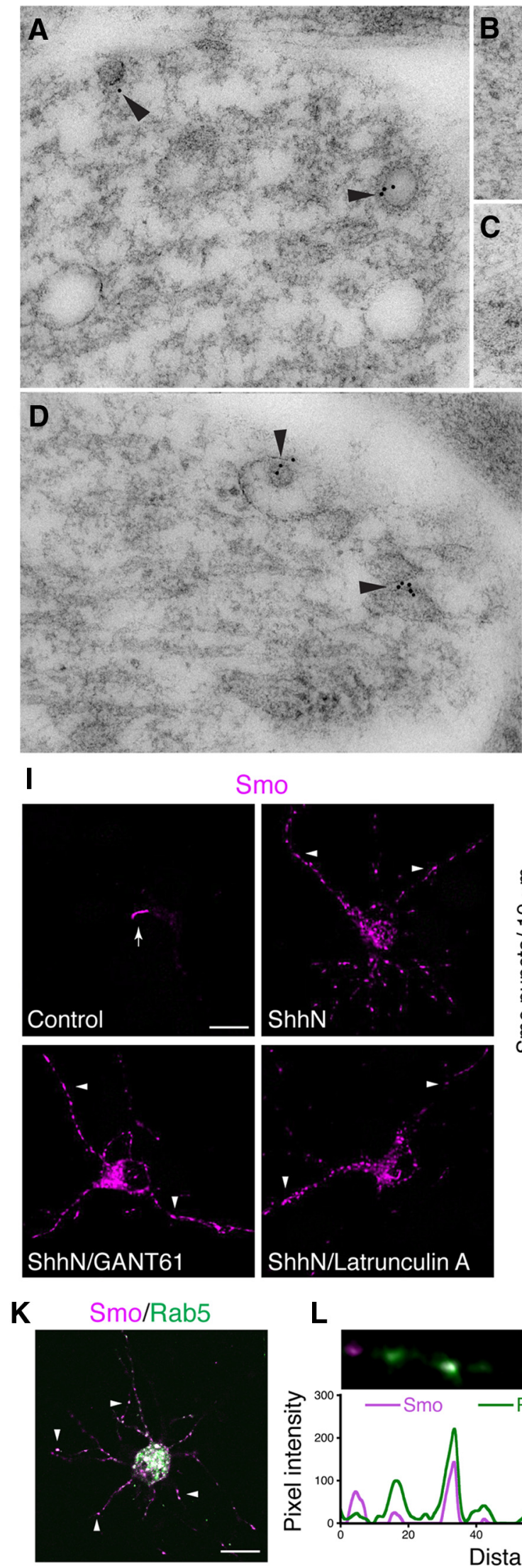

L

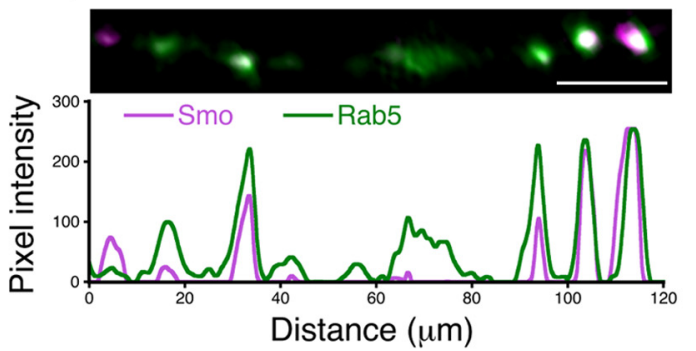

M
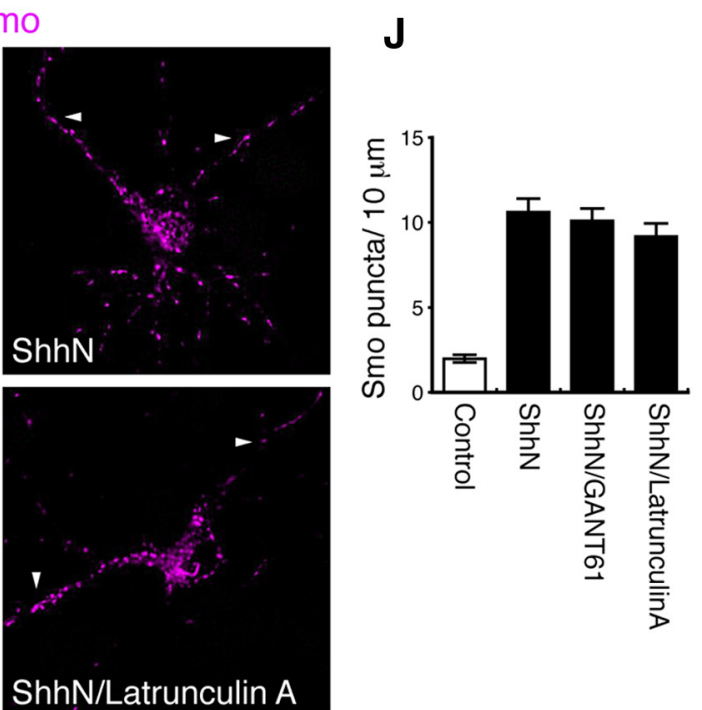

$50 \mathrm{sec}$

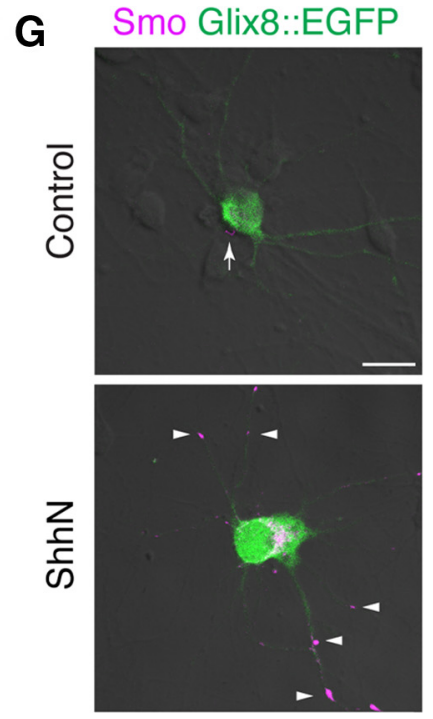

H

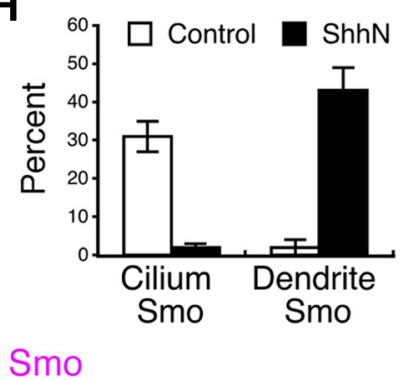

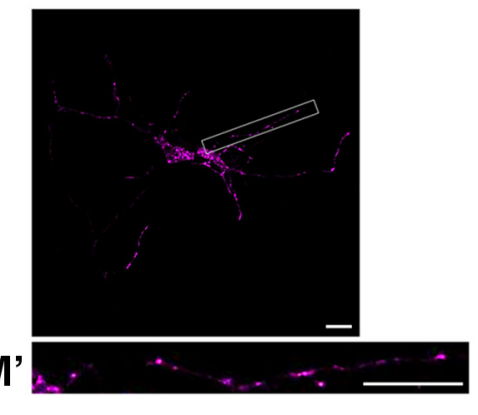
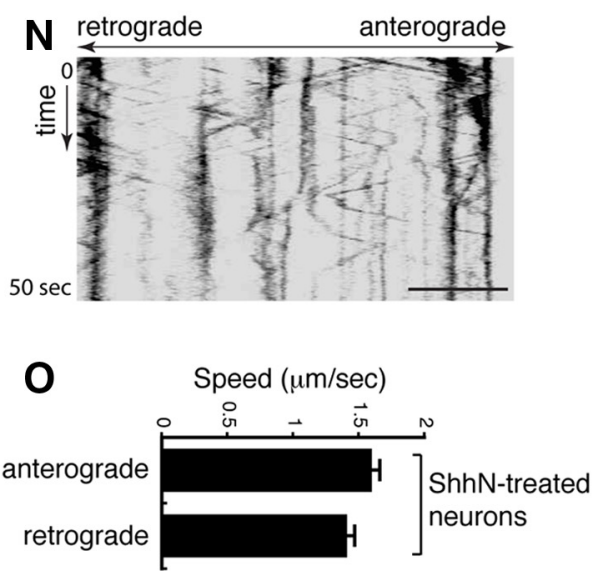

Figure 5. Distribution and trafficking of $S m$ o in the dendrites of hippocampal neurons. $\boldsymbol{A}-\boldsymbol{F}$, Immunogold (10 nm) labeling of $S \mathrm{mo}$ in postnatal day 2 rat hippocampus $(\mathrm{A} 1 \mathrm{stratum}$ radiatum $(\boldsymbol{A}$, $\boldsymbol{B}, \boldsymbol{D}, \boldsymbol{E})$, the molecular layer of the dentate gyrus $(\boldsymbol{F})$, and the ventricular zone $(\boldsymbol{C})$. Smo labeling is found on clathrin-coated pits and vesicles $(\boldsymbol{A}-\boldsymbol{C} ;$ arrowheads) and in early/sorting endosomes $(\boldsymbol{D}-\boldsymbol{F}$; arrowheads) in dendrites $(\boldsymbol{A}, \boldsymbol{D}-\boldsymbol{F})$ and other cellular processes $(\boldsymbol{B}, \boldsymbol{C})$. Scale bar, $100 \mathrm{~nm}$. $\mathbf{G}$, Representative images of hippocampal neurons cotransfected with Smo::tdTomato (magenta) and Glix8::EGFP (green) and treated with ShhN for $1 \mathrm{~d}$. In control neurons, Smo::tdTomato is concentrated in the primary cilium (white arrow), whereas in ShhN-treated (Figure legend continues.) 
localized receptors, we investigated the role of primary cilia in mediating the Shh-induced axon elongation of hippocampal neurons.

In the initial stage of this work, we characterized several markers for revealing the primary cilium in cultured hippocampal neurons, using antibodies specific to acetylated $\alpha$-tubulin (acTub; Wheatley et al., 1996), adenylate cyclase III (ACIII; Bakalyar and Reed, 1990), and Arl13b (Caspary et al., 2007). Immunolabeling of acTub is commonly used to mark the primary cilium in several non-neuronal cell types such as NIH 3T3 fibroblasts and mouse embryonic fibroblasts (for examples, see Fan et al., 2014 and Chong et al., 2015). In hippocampal neurons, however, we observed widely expressed acTub throughout the cell bodies and neurites, preventing its use as a marker for visualization of cilia in neurons (also see Berbari et al., 2007). Conversely, antibodies to ACIII, RPCA-ACIII, and Arl13b worked well in revealing primary cilia in neurons. We therefore used ACIII as the cilium marker in this study (Fig. $4 A, A^{\prime}$ ).

In young, developing neurons at the stage when axons grow rapidly (1-3 DIV), we found that only $\sim 20 \%$ of cells had ACIIIimmunolabeled cilia (Fig. $4 A, B$ ). This finding is in agreement with the observation made by Berbari et al. (2007). In addition, we found that treatment with ShhN or SAG did not change the number of neurons that had ACIII-labeled cilia (Fig. 4B).

As hippocampal neurons grew in culture, we noticed that more neurons bore a primary cilium. From 8 to $22 \mathrm{DIV}, \sim 80 \%$ of neurons were found to have ACIII-labeled primary cilia (Fig. $4 C)$. The length of the cilium also increased as neurons matured, from $\sim 2 \mu \mathrm{m}$ at 2 DIV to nearly $8 \mu \mathrm{m}$ at 15 DIV (Fig. $4 D$ ). Interestingly, from 2 through $22 \mathrm{DIV}$, ShhN treatment did not affect either the number of cilium-bearing neurons or the length of the cilia (Fig. 4C,D).

Given that the majority of developing neurons (at 2 DIV) lacked cilia and that the growth of cilia was unaffected by ShhN treatment, we next compared axon outgrowth from neurons that contained or lacked a cilium (Fig. 4E-H). We observed that ShhN promoted axon elongation in neurons regardless of the presence or absence of a detectable ACIII-immunolabeled cilium (Fig. 4EI). We repeated the assessment of axon growth during the first 3 DIV and observed increased axon growth in both the ciliated and unciliated Shh-treated cells (Fig. 4I). These results suggest that Shh may act independently of primary cilia to promote axon elongation.

\footnotetext{
$\leftarrow$

(Figure legend continued.) neurons, many Smo::tdTomato puncta (arrowheads) spread to dendrites. Scale bars, $20 \mu \mathrm{m}$. $\boldsymbol{H}$, Quantitative comparison of cilium Smo versus dendritic Smo in control and ShhN-treated cells. Data are expressed as percentage of transfected cells. $n>30$ neurons from three cultures. I, Representative images of neurons expressing Smo::tdTomato (magenta). White arrow points to Smo-containing primary cilium; white arrowheads point to Smo puncta scattered along dendrites. Notice that neither GANT61 $(10 \mu \mathrm{M})$ nor latrunculin A $(0.48 \mu \mathrm{M})$ appears to change the overall Shh-elicited Smo distribution in dendrites. Scale bar, 20 $\mu \mathrm{m} . J$, Quantitative analysis of $I . n \geq 30$ neurons from three cultures. $\boldsymbol{K}$, Representative image of neurons coexpressing Smo::tdTomato (magenta) and Rab5::turquoise (green). White arrowheads point to Smo puncta scattered along dendrites. Scale bar, $20 \mu \mathrm{m}$. $L$, Fluorescence intensity profile of a dendritic segment expressing Smo::tdTomato (magenta) and Rab5::turquoise (green) shows largely colabeling of Smo and Rab5 in endosomes. Scale bar, $20 \mu \mathrm{m}$. M, Timelapse analysis of Smo movement in ShhN-treated neurons. Image shows the first frame of a time-lapse movie from a ShhN-treated neuron expressing Smo::tdTomato. $\boldsymbol{M}^{\prime}$ is the enlarged view of the boxed area in $\boldsymbol{M}$. Scale bars, $25 \mu \mathrm{m}$. $\boldsymbol{N}$, Kymograph generated from this region shows positively and negatively sloping lines, indicating that $S$ mo moves in both the anterograde and retrograde directions. Scale bar, $25 \mu \mathrm{m}$. 0, Quantitative analysis of the speed of Smo movement. $n=8$ neurons from two cultures.
}

\section{Shh promotes Smo trafficking in dendrites of hippocampal neurons}

Our previous immunoelectron microscopy showed that, in addition to the primary cilium, most Smo molecules in hippocampal neurons localize to the dendrites (Petralia et al., 2011a). We examined the dendrites of these neurons further and found that Smo immunogold particles associated directly with several types of trafficking and signaling organelles, including clathrin-coated pits and vesicles (Fig. 5A,B) and early or sorting endosomes (Fig. $5 C-F)$.

To determine the distribution pattern and the trafficking behavior of Smo in the landscape of an entire hippocampal neuron, we expressed hippocampal neurons ectopically with tdTomatotagged Smo. We first examined neurons coexpressing Smo::tdTomato and Glix8::EGFP (Fig. 5G). In untreated control neurons, detectable Smo::tdTomato was seen more frequently in the primary cilium (Fig. $5 G-I$ ) than in the proximal parts of the dendrites (arrowheads in Fig. 5I, top). After ShhN treatment, however, a large number of Smo::tdTomato puncta were found in the dendrites of many neurons (Fig. $5 G-I$ ). It is possible that the dendrites are the active Shh-signaling regions and that Smo relocates to participate in Shh signal transduction in dendrites.

We next cotreated Smo::tdTomato-expressing neurons with ShhN and the Gli inhibitor GANT61 (Lauth et al., 2007). GANT61 $(10 \mu \mathrm{M})$ did not seem to affect Shh-elicited dendritic Smo distribution (Fig. 5I,J). Similarly, when neurons were treated with ShhN in the presence of latrunculin A $(0.48 \mu \mathrm{M})$, a drug that sequesters actin monomers, the overall dendritic Smo distribution was not visibly different from ShhN-only control (Fig. 5I,J). Therefore, Shh-induced Smo distribution in the dendrite appears to be independent of Gli and may not require actin.

We next examined neurons coexpressing Smo::tdTomato and Rab5::EGFP, a marker for early endosomes. Smo puncta, particularly those located in the cell body and dendrites, largely colocalized with Rab5-marked endosomes (Fig. $5 K, L$ ). We then performed live-cell imaging experiments (Fig. $5 M, M^{\prime}$ ). We focused on examining ShhN-treated neurons and analyzed two transport properties of Smo in dendrites: direction and velocity. Kymograph analysis (Fig. $5 \mathrm{~N}$ ) showed that Smo puncta in dendrites move in both anterograde $(1.63 \mu \mathrm{m} / \mathrm{s})$ and retrograde $(1.43 \mu \mathrm{m} / \mathrm{s}$ ) directions (Fig. 5O).

\section{Shh pathway activation increases profilin 1 protein level}

Shh signaling initiates a transcriptional response that is mediated by the Gli family of transcription factors. Inhibiting Gli1 activity with GANT1 prevented increased axonal length in response to Shh (Fig. $2 H, I$ ). We know that activation of the pathway in young hippocampal neurons stimulates transcription of Ptch and Gli1 (Fig. 1A) and we predicted that upregulation of additional cellular components mediates the axon growth response.

In an initial survey, we noticed that the level of mRNA for Pfn1 was increased in ShhN-treated neurons (2.63-fold from 3 biological replicates by microarray and average 2.95 -fold from 4 biological replicates by qRT-PCR). Profilins are evolutionarily conserved actinbinding proteins that are best known for their role in regulating actin polymerization (Carlsson et al., 1977; Witke, 2004). Pfn1 protein increased rapidly in hippocampal neurons during the first $3 \mathrm{~d}$ in culture (Fig. 6A,B), a period coinciding with active axon outgrowth in these neurons (Fig. 2D; Banker and Goslin, 1988). Remarkably, adding ShhN to the cultures induced a still further and significant increase in Pfn1 protein abundance (Fig. 6A,B). This increase was consistently observed from 4-6 independent experiments. 
To determine whether Pfn1 was a direct Gli target, we analyzed the regulatory sequences for Pfn1. We did not find any consensus Gli-binding sites (Kinzler and Vogelstein, 1990) in the $10 \mathrm{~kb}$ upstream nor in the $100 \mathrm{bp}$ downstream from the transcription start site. Two scenarios could explain this: (1) there is an unconventional Gli-binding site that serves as a promoter for Gli1 or (2) Gli1 promotes the production of an intermediate factor that in turn regulates Pfn 1 transcription or translation.

Because the ShhN-elicited increase in Pfn1 protein level was particularly evident in the first $2 \mathrm{~d}$, we performed more experiments during this early period of axon outgrowth. To verify that the ShhN-stimulated Pfn1 increase depended on Smo, we tested the effects of SAG and cyclopamine. SAG (400 nM) increased the Pfn1 level, averaging $\sim 4$.4-fold from 4 independent experiments (Fig. 6C,D). Cyclopamine, when added together with ShhN, reduced the Pfn 1 protein down to the basal level in some cases (Fig. $6 C$, left blot) and below the basal level in other cases (Fig. $6 C$, right blot). When cyclopamine was given to neurons alone, it lowered Pfn 1 abundance below the basal level of untreated control neurons (Fig. 6E). We also evaluated whether Gli was involved using the Gli inhibitor GANT61. GANT61 prevented the ShhN-elicited Pfn1 increase at low doses and suppressed total Pfn1 levels at higher doses (Fig. 6C,F). These results suggest that, in hippocampal neurons, the ShhN-increased $\mathrm{Pfn} 1$ protein level and the constitutive basal level of Pfn 1 depend on Smo and Gli.

To answer the question of whether increased Pfn 1 expression level was specifically induced by Shh pathway activity, we examined Pfn 1 protein levels in neurons that were treated with BDNF. We chose to compare Shh to BDNF for two reasons. First, using a similar cultured hippocampal neuron system, BDNF has been shown to be a potent growth factor in stimulating axon growth (Cheng et al., 2011). Second, BDNF signaling pathway does not seem to interact directly with Shh signaling pathway because BDNF does not induce Glil expression (Fig. $1 B, C$ ) and adding ShhN to neurons also does not increase BDNF level (P.J.Y., unpublished data). We treated hippocampal neurons with BDNF (50 ng/ml) from 1-3 d, as we did with Shh treatment. Unlike Shh, BDNF did not increase Pfn 1 protein level at any time point (Fig. $6 G$ ). The increased level of phosphorylated CREB in BDNFtreated neurons validated BDNF's activity.

We also wanted to know whether Shh activity increased Pfn1 protein in cells other than neurons. We chose NIH3T3 fibroblasts because they are known to respond to Shh activity (Taipale et al., 2000; Chen et al., 2002a,b; Hyman et al., 2009; Fan et al., 2014). Unlike their effect on hippocampal neurons, ShhN or SAG did not appear to affect Pfn 1 abundance in NIH3T3 cells (Fig. 6H,I) despite their robustly elevating the Glil level, a readout of the activated Shh pathway (Fig. $6 H$ ). Unlike its effect on hippocampal neurons, cyclopamine did not reduce the Pfn1 level in 3T3 cells (Fig. $6 H, I$ ).

Of the four known Pfn isoforms in mammalian cells, Pfn 1 is expressed ubiquitously (Witke, 2004; Birbach, 2008). Another Pfn isoform, Pfn2a, is believed to be brain specific (Witke, 2004; Birbach, 2008; Michaelsen et al., 2010). To determine whether the Shh-induced effect was specific to Pfn1, we examined Pfn2a. As expected, Pfn2a was detected in hippocampal neurons; however, its level was not affected by ShhN treatment (Fig. 6J, K).

We also examined cofilin, an actin filament-severing protein (Carlier et al., 1999) that has been implicated in neurite growth (Flynn et al., 2012; Yamauchi et al., 2013). When we measured the active form of cofilin (Arber et al., 1998; Yang et al., 1998), which has an unphosphorylated serine 3 (Ser3), we did not detect a discernible difference in its abundance between ShhN-treated neurons and untreated neurons (Fig. $6 L, M$ ). However, when we measured Ser3-phosphorylated cofilin, a catalytically inactive form (Arber et al., 1998; Yang et al., 1998), we found that its level in ShhN-treated neurons was significantly higher than in untreated controls (Fig. $6 \mathrm{~N}, \mathrm{O}$ ). Furthermore, treatment with cyclopamine clearly blocked the ShhN-induced effect and, in fact, reduced phosphorylated cofilin below the control level (Fig. $6 N, O)$. Likewise, GANT61 also markedly lowered phosphorylated cofilin abundance to a nearly undetectable level (Fig. $6 \mathrm{~N}, \mathrm{O})$.

\section{Profilin 1's actin binding ability is necessary for Shh-induced axon elongation}

To investigate whether increasing Pfn1 levels can affect the length of axons in developing hippocampal neurons, we overexpressed Pfn1 in these neurons. We transfected neurons at 2 DIV and examined them 1 d later (Fig. 7A). We chose to use 2 DIV neurons because of their better transfection efficiency than 0 or 1 DIV neurons. We found that overexpression of WT Pfn 1 produced significantly longer axons (Fig. $7 B$ ). The average axon length of neurons expressing WT Pfn 1 was $272 \pm 18 \mu \mathrm{m}$, whereas the average axon length of neurons expressing a control vector was $222 \pm 13 \mu \mathrm{m}(n=30, p=0.031)$.

We next compared the axon length of neurons overexpressing Pfn1 mutants. Pfn1 mutants C71G, E117G, G118V, and M114T occur in patients with familial amyotrophic lateral sclerosis (ALS) (Wu et al., 2012). For comparison, we used a synthetic Pfn1 mutant H120E because this mutation is known to disrupt Pfn1 blinding to actin (Suetsugu et al., 1998). Among the ALSrelated Pfn1 mutants, three of them retained the axonlengthening effect of WT Pfn1 (Fig. 7B). In contrast, the expression of the Pfn 1 mutant $\mathrm{C} 71 \mathrm{G}$ no longer lengthened the axons and this loss of axon lengthening was similarly observed in neurons expressing the Pfn 1 H120E mutant (Fig. 7B). Interestingly, patients with the Pfn 1 C71G mutation exhibit a more aggressive early-onset disease compared with other ALS-related Pfn1 mutations (Wu et al., 2012). Furthermore, loss of actin binding of the $\mathrm{C} 71 \mathrm{G}$ has been noted in motor neurons (Wu et al., 2012).

We also compared the effect of ShhN-induced axon elongation between neurons expressing Pfn $1 \mathrm{C} 71 \mathrm{G}$ and a control vector. Neurons expressing Pfn 1 C71G were refractory to the ShhNinduced axon lengthening effect (Fig. 7C,D). Upon ShhN treatment, the average axon length of C71G-expressing neurons was $228 \pm 27 \mu \mathrm{m}(n \geq 30)$, whereas the average axon length of vector expressing neurons was $330 \pm 27 \mu \mathrm{m}(n \geq 30)$. Likewise, expression of the Pfn $1 \mathrm{H} 120 \mathrm{E}$ mutant prevented ShhN-induced axon lengthening (Fig. 7D).

The above results suggest that Pfnl's actin binding is important for the Shh-induced axon lengthening. Given that the primary function of profilins is to regulate actin polymerization, we treated neurons with $\mathrm{ShhN}$ in the presence of latrunculin $\mathrm{A}$, a drug that prevents actin polymerization (Fig. $7 E$ ). When we treated neurons with latrunculin $\mathrm{A}(0.48 \mu \mathrm{M})$ alone, the length of axons was similar to that of the control (no latrunculin A), but many axons displayed curved or looped trajectories (Fig. 7F). When we treated neurons with latrunculin A together with ShhN, latrunculin A blocked ShhN-elicited axon lengthening (Fig. 7G).

\section{Profilin1 mediates Shh-induced axon elongation}

The above results show that neurons overexpressing WT Pfn1 grow longer axons. We next knocked down Pfn 1 protein levels using RNA interference to determine the roles of endogenous 


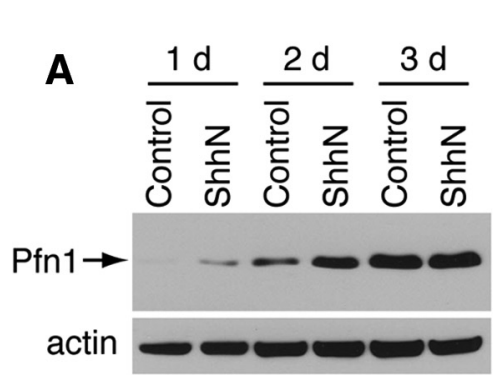

B
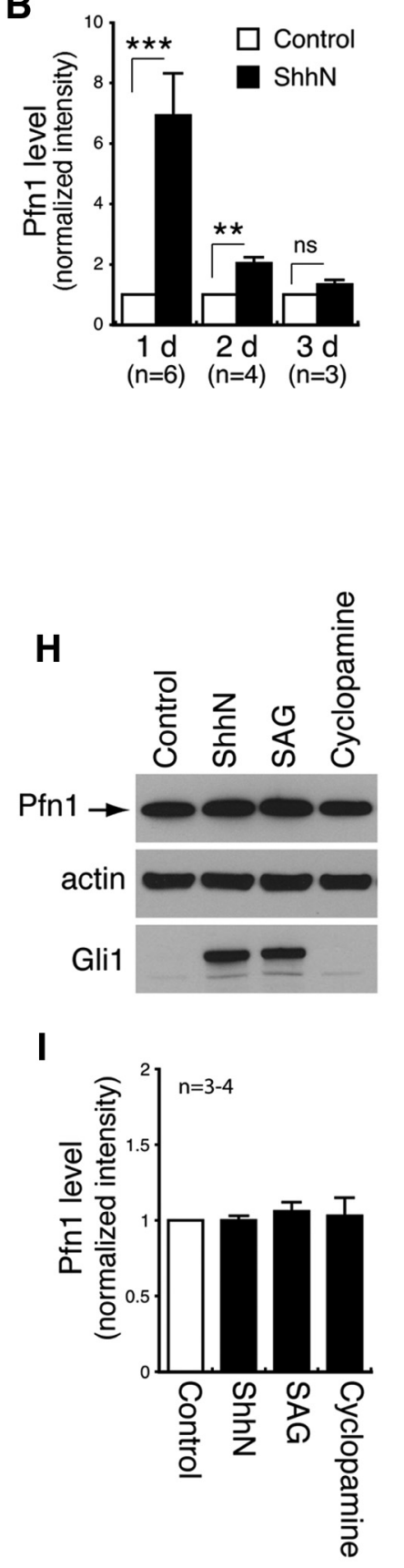
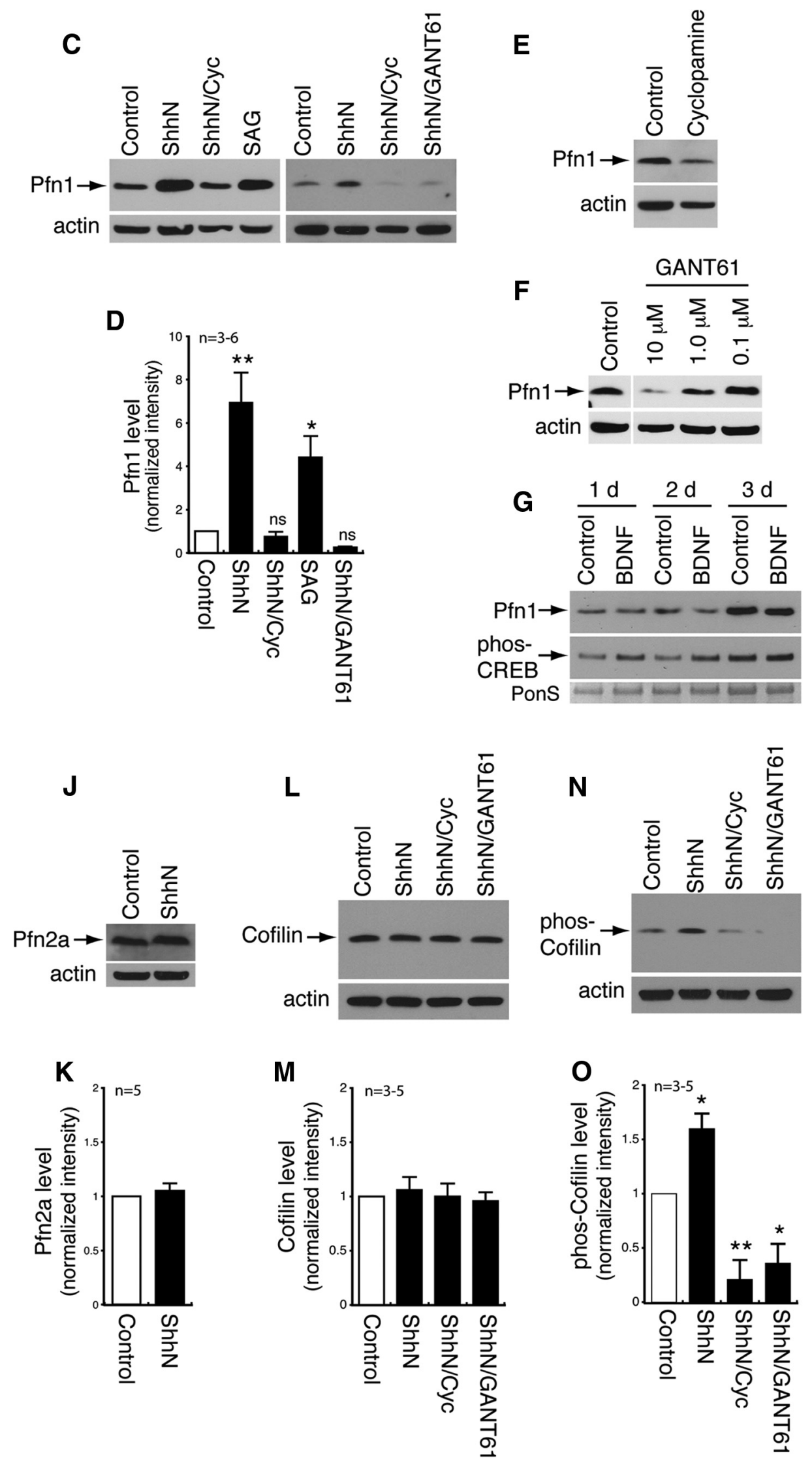

Figure 6. Shh signaling increases profilin 1 levels in hippocampal neurons. $A$, Neurons were treated with ShhN for $1-3 \mathrm{~d}$. Representative immunoblot shows that Pfn 1 levels increase during a $3 \mathrm{~d}$ time period and that ShhN upregulates Pfn1 protein expression. B, Quantification of $\boldsymbol{A}$ showing increased Pfn1 levels in ShhN-treated neurons. $n=3-6$ separate cultures. $\boldsymbol{C}$, Representative immunoblots show that, similar to ShhN, SAG (400 nM) increases Pfn 1 levels and that cyclopamine (Cyc, $10 \mu \mathrm{M})$ and GANT61 (10 $\mu \mathrm{m})$ block the ShhN-induced increase of Pfn 1 levels. D, Quantification of $\boldsymbol{C} . n=3-6$ separate cultures. $\boldsymbol{E}$, Representative immunoblot showing that cyclopamine (10 $\mu \mathrm{m})$ treatment alone reduces Pfn1 level in neurons. $\boldsymbol{F}$, (Figure legend continues.) 
Pfn1 in basal and Shh-induced axon growth. Among several Pfn1 shRNA candidates tested, one of them (shRNA \#49) consistently and effectively reduced Pfn 1 protein levels. Figure $8 A$ shows an example of the Pfn 1 shRNA-expressing neurons in which Pfn1 immunolabeling was not visible. Figure $8 B$ shows significantly reduced $\mathrm{Pfn} 1$ levels in neurons infected with a lentiviral construct that harbored the same Pfn1 shRNA. Using this Pfn1 lentiviral shRNA construct, we examined the effect of reduced Pfn 1 on ShhN-induced axon growth using the compartmentalization culture system (Fig. 8C). We found that axon length and density of ShhN-treated, Pfn 1 shRNA-infected neurons were significantly less than the axons of ShhN-treated, control shRNA-infected neurons as deduced from fluorescence intensity of the immunolabeled axons (Fig. 8D,E). A comparison of axon density between ShhN-treated neurons and controls showed that the reduction of Pfn1 in developing hippocampal neurons prevents Shhmediated induction of axon elongation (Fig. $8 F$ ).

Finally, to test whether dendritic distribution of Smo requires Pfn 1, we cotransfected neurons with Pfn 1 shRNA and Smo::tdTomato and evaluated Smo distribution. As shown in Figure 8, $G$ and $H$, the Shh-elicited Smo distribution was similar in neurons expressing the Pfn 1 shRNA and the control shRNA. Together, these findings suggest that Pfn1 upregulation induced by Shh signaling contributes to axon growth but does not have a detectable effect on Smo distribution in dendrites.

\section{Discussion}

In addition to its role in embryonic tissue patterning (Ingham and McMahon, 2001; Varjosalo and Taipale, 2008), the ability of the Shh signaling pathway to regulate neuronal connectivity both during and after development has been observed in many parts of the nervous system (Wallace, 1999; Wechsler-Reya and Scott, 1999; Dahmane and Ruiz i Altaba, 1999; Kunes, 2000; Lewis et al., 2004; Umetsu et al., 2006; Okada et al., 2006; Sanchez-Camacho and Bovolenta, 2008; Chou et al., 2010; Gonzalez-Reyes et al., 2012; Harwell et al., 2012; Yam and Charron, 2013; Persson et al., 2014; De Luca et al., 2015). In the neurons of the hippocampus, Shh and the required downstream signaling elements are known to be present (Traiffort et al., 1999; Sasaki et al., 2010; Petralia et al., 2011a,b; Mitchell et al., 2012). Here, using dissociated-cell cultures of rat hippocampal neurons as a model system, we find that the activation of the Shh pathway stimulates the extension of the axon. The Shh-elicited effect on axons depends on Smo and

\footnotetext{
$\leftarrow$

(Figure legend continued.) Representative immunoblots showing that GANT61 reduces the Pfn1 level in a dose-dependent manner. G, Immunoblots showing that the Pfn1 protein level is not increased in neurons treated with BDNF $(50 \mathrm{ng} / \mathrm{ml})$. The level of phosphorylated CREB is increased in the same BDNF-treated samples (evident in the $1 \mathrm{~d}$ and $2 \mathrm{~d}$ treatment), validating BDNF's bioactivity. Ponceau red stain of the blot was used for evaluating protein loading among samples and a strip of Ponceau red (PonS) is shown. The experiment was performed two times with independent cultures. $\boldsymbol{H}$, Representative immunoblots showing that Pfn1 level in 3T3 cells - unlike in neurons - is not noticeably affected by ShhN activity. SAG, 400 nm; cyclopamine, $10 \mu \mathrm{m}$. I, Quantification of $\boldsymbol{H} . n=3-4$. J, Representative immunoblot showing that, unlike Pfn1, the level of Pfn2a is not affected by ShhN treatment. $\boldsymbol{K}$, Quantification of $\boldsymbol{J} . n=5$ separate cultures. $L$, Representative immunoblot showing that Shh signaling does not affect the level of cofilin protein in hippocampal neurons. $\boldsymbol{M}$, Quantification of $\boldsymbol{L}$. $n=3-5$ separate cultures. $\boldsymbol{N}$, Representative immunoblot showing that the amount of phosphorylated cofilin is increased in ShhN-treated neurons and is reduced in neurons cotreated with ShhN and cyclopamine $(10 \mu \mathrm{m})$ or ShhN and GANT61 $(10 \mu \mathrm{m}) . \mathbf{0}$, Quantification of $\boldsymbol{N} . n=3-5$ separate cultures. Error bars indicate SEM. ${ }^{* * *} p<0.001,{ }^{* *} p<0.01,{ }^{*} p<0.05$, unpaired $t$ test. ns, Not significant.
}

Gli1, but occurs regardless of whether the neurons have developed a primary cilium.

The experiments in this study have focused on the events occurring in hippocampal neurons in response to experimentally provided Shh. Although our findings demonstrate that the Pfn1 level (Fig. $8 F$ ) or Pfn1-actin interaction (Fig. $7 B, D$ ) is important for the accelerated axon growth induced by exogenously added Shh, Pfn 1 does not seem to be essential for axon growth that depends on basal endogenous Shh signaling activity. A remaining question, then, is how the endogenous level of Shh signaling is regulated in the hippocampus. Because Shh secretion can be induced in a neuronal cell line upon depolarization (Beug et al., 2011), one possibility is that neuronal activity could be one of the endogenous, physiological factors that controls Shh signaling activity.

The temporal and morphological features of axon growth in cultured hippocampal neurons have been characterized meticulously (Banker and Goslin, 1988). In elucidating the mechanism of Shh signaling and axon growth, these cultured neurons offer an additional and unique advantage. During the first few days in culture - the age when young neurons actively grow their axons-only a fraction of these neurons $(\sim 20 \%)$ contain the primary cilia (Fig. 4; and Berbari et al., 2007). Because the primary cilium is thought to be the signaling center for Shh signal transduction in non-neuronal cells (Caspary et al., 2007; 2011; Beales and Jackson, 2012; Louvi and Grove, 2011) and some neurons (Breunig et al., 2008; Spassky et al., 2008; Baudoin et al., 2012; Willaredt et al., 2013), we reasoned that the observed Shhstimulated axon growth should take place only in the ciliumbearing neurons. Surprisingly, our results reveal that Shh induces axon elongation in young hippocampal neurons regardless of whether they bear cilia. It is possible that ACIII, a commonly used neuronal ciliary marker, does not mark all populations of the cilia in young hippocampal neurons. For this reason, we have compared the neurons labeled with additional ciliary markers, including RPCA-ACIII and Arl13b (Berbari et al., 2007; Caspary et al., 2007). Results from using all three ciliary markers consistently show $\sim 20 \%$ of young cultured hippocampal neurons with cilia. To prove definitively that the cilia are not required for Shhelicited axon elongation, we would need to remove the primary cilia experimentally and then assess axon growth of such neurons in response to Shh. A major caveat of such studies, however, is that the experimental approaches used to remove or disrupt the cilia could also disturb other components of the neurons or interfere with some neuron-specific functions or properties such as axon growth. Therefore, further studies are needed to thoroughly and rigorously characterize the specificity of the existing, as well as any new, cilium-disrupting reagents and methods.

It is interesting to note that, despite being molecularly unrelated proteins, Pfn 1 exhibits two surprising similarities with Bassoon and Neuropilin1. All three proteins have been suggested to regulate axon growth, albeit in different contexts and at a different developmental stages. Pfn1 is required for the axon outgrowth of motor neurons, as demonstrated by studies from Drosophila Pfn mutants (Wills et al., 1999) and from patients with mutations in the Pfn 1 gene (Wu et al., 2012). Bassoon is a presynaptic active zone protein and its mutation causes defective hippocampal mossy fibers (Lanore et al., 2010). Neuropilin family proteins have been invoked as axon guidance proteins in diverse types of neurons (He and Tessier-Lavigne, 1997; Kolodkin and Ginty, 1997). Another similarity among Pfn1, Bassoon, and Neuropilin1 is their unconventional response to Shh signaling activity. None of their genes contains the consensus-binding se- 
A

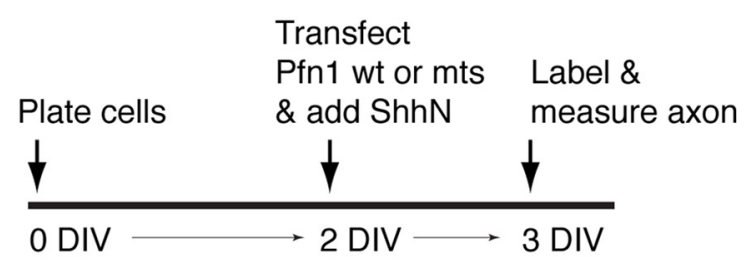

C
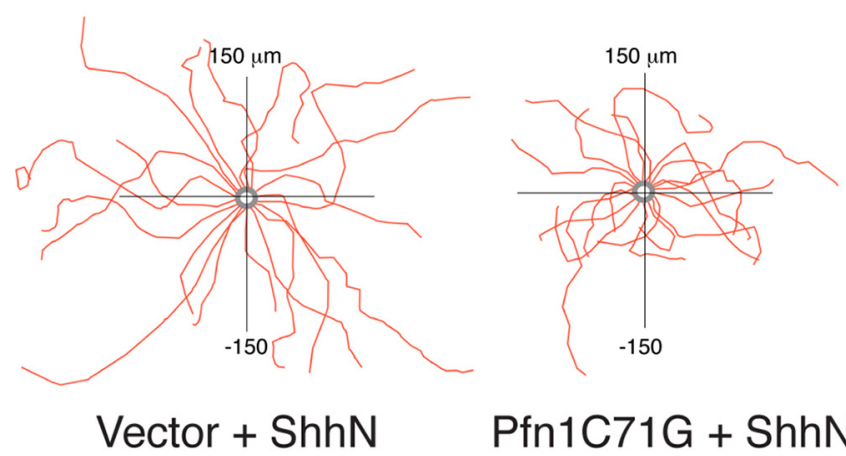

Pfn1C71G + ShhN
B

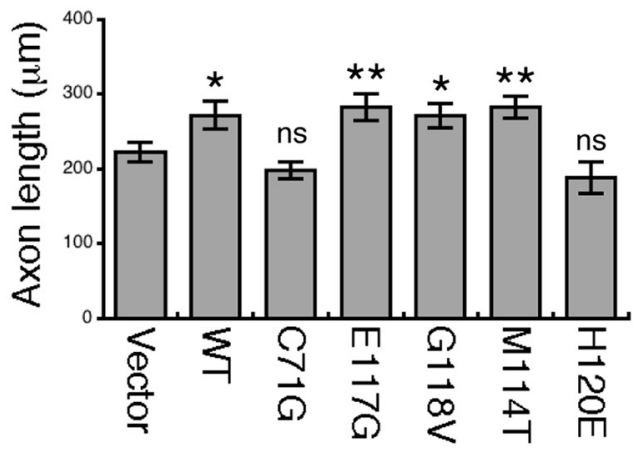

D

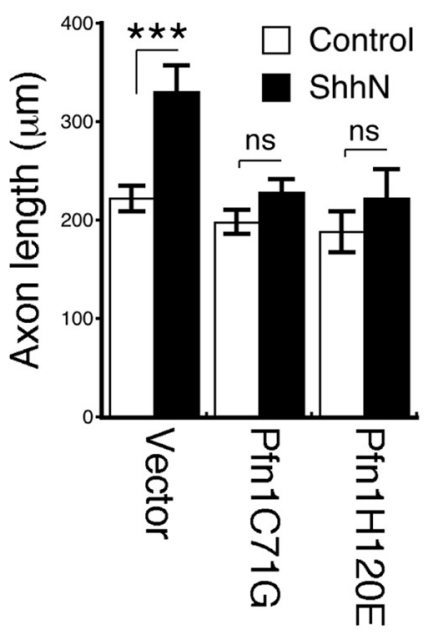

E

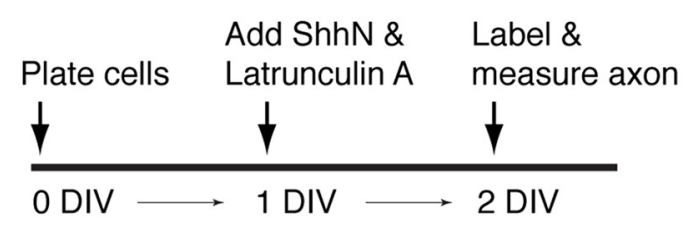

G

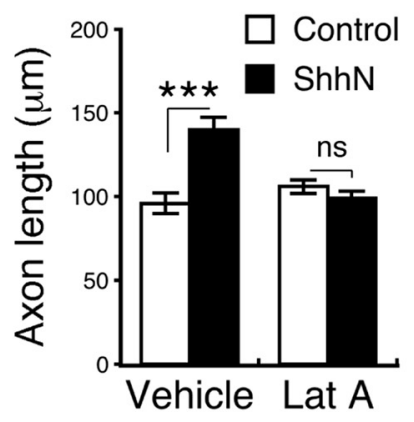

F

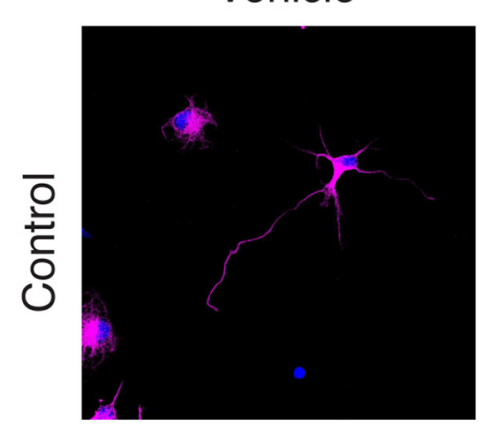

Latrunculin A
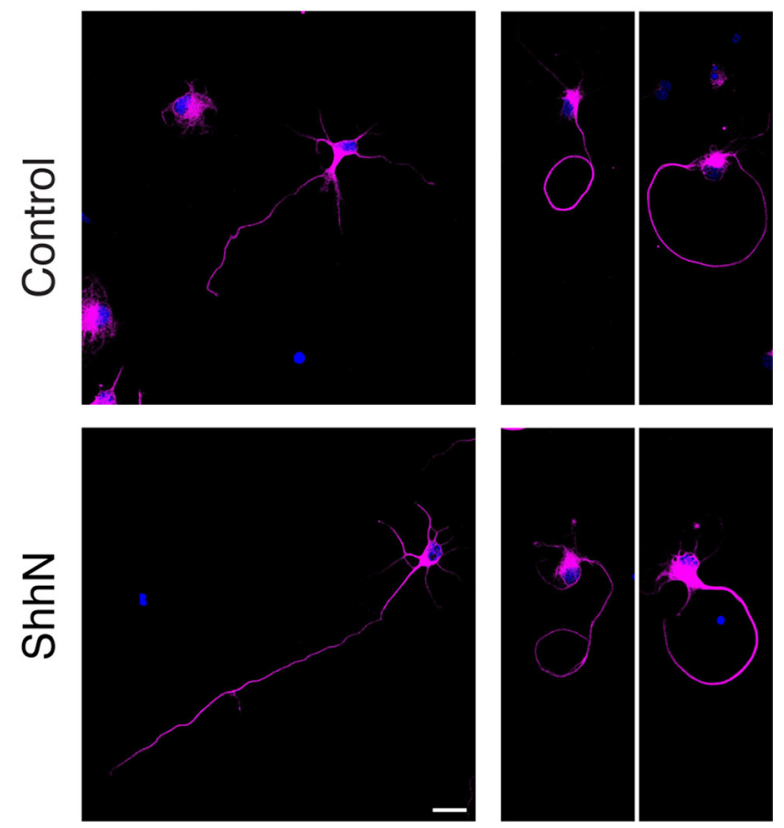

Figure 7. Pfn1 actin binding is necessary for ShhN-induced axon elongation. $\boldsymbol{A}$, Experimental design. $\boldsymbol{B}$, Comparison of axon length between neurons expressing WT Pfn 1 and the indicated Pfn1 mutants. In this experiment, neurons were not treated with ShhN. Notice that overexpression of WT Pfn increases axon length. Three of the Pfn1 mutants (E117G, G118V, and M114T) also increase axon length. The Pfn 1 mutants $(71 \mathrm{G}$ and H120E do not increase axon length. $n>30$ neurons from three to five cultures. $C$, Compiled traces of axons from neurons that were transfected with either a control vector or Pfn1 mutant C $71 \mathrm{G}$ and treated with ShhN. Neurons expressing C71G do not grow longer axons in response to ShhN. $\boldsymbol{D}$, Quantification of axon lengths in control and ShhN-treated neurons transfected with empty vector, Pfn 1 mutant $71 \mathrm{G}$, or Pfn1 mutant H120E. $n \geq 30$ neurons from three to five cultures. $E$, Experimental design for the latrunculin A experiment. $F$, Sample images of neurons treated with $S h h N$ in the presence of vehicle or latrunculin A $(0.48 \mu \mathrm{M})$. Neurons were labeled with Tuj1 (magenta). Scale bar, $10 \mu \mathrm{m}$. G, Quantification of $\boldsymbol{F} . n=30$ neurons from three cultures. Error bars indicate SEM. ${ }^{* * *} p<0.001,{ }^{* *} p<0.01,{ }^{*} p<0.05$, unpaired $t$ test. ns, Not significant. 
A GFP::
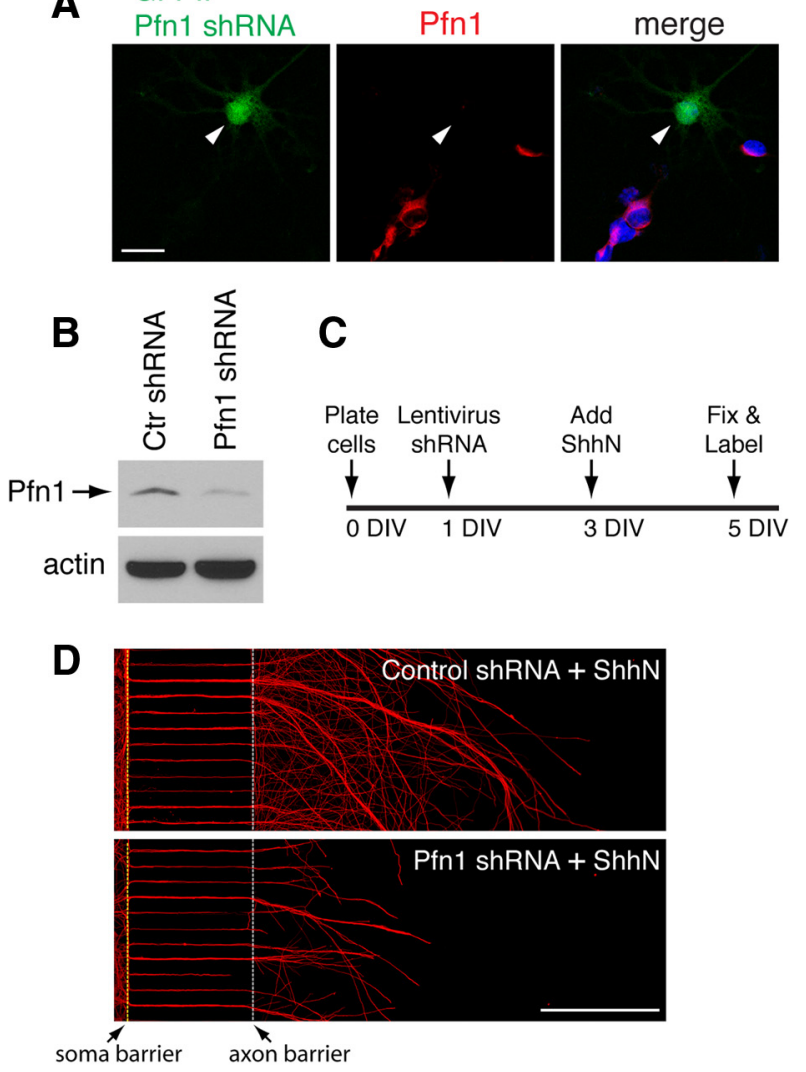

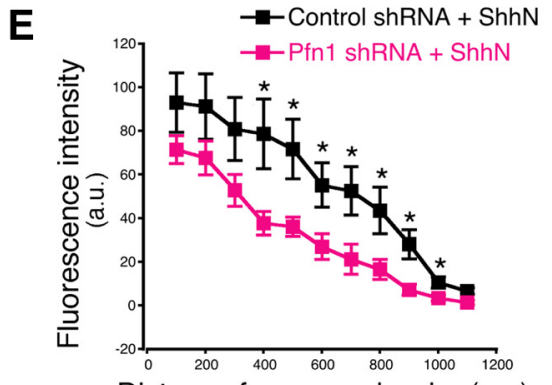

Distance from axon barrier ( $\mu \mathrm{m})$

G
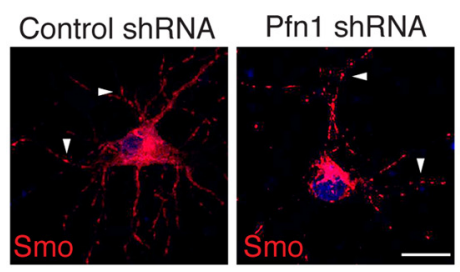

$\mathbf{F}$

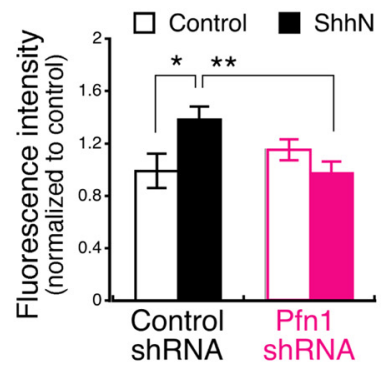

$\mathrm{H}$

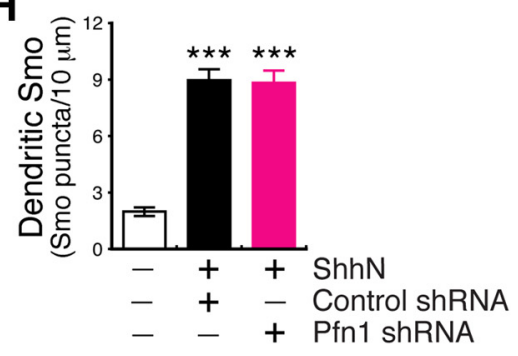

Figure 8. Shh-induced axon elongation requires Pfn1. $\boldsymbol{A}$, Representative images of hippocampal neurons transfected by an EGFP construct harboring the shRNA \#49. Arrowheads point to a Pfn1 shRNA-expressing hippocampal neuron (green) with Pfn1 expression (red) undetectable. Scale bar, $20 \mu \mathrm{m}$. B, Immunoblot analysis of lentivirus-infected hippocampal neurons expressing a control shRNA or the Pfn1 shRNA \#49. C, Experimental design. The effect of Pfn1 knock-down on Shh-induced axon elongation was assessed in neurons grown in a compartmentalized system. $\boldsymbol{D}$, Representative images of Tuj1 (red)-labeled hippocampal neurons infected with either the control or Pfn1 shRNA lentivirus. ShhN was added exclusively to the somatodendritic compartment. Scale bar, $450 \mu \mathrm{m}$. $\boldsymbol{E}$, Average intensity of Tuj1 immunolabeling in $\boldsymbol{D}$ along a $1200 \mu \mathrm{m}$ distance starting from the axon barrier (white dashed line) was measured and normalized to the intensity at the soma barrier (yellow dashed line). $\boldsymbol{F}$, Comparison of axon density in $\boldsymbol{D}$ as measured by Tuj1 immunolabeling intensity between hippocampal neurons expressing the control and Pfn1 shRNA. G, Representative images of neurons coexpressing Smo::tdTomato and either control shRNA or Pfn1 shRNA. White arrowheads point to dendritic Smo puncta. Scale bar, $20 \mu \mathrm{m}$. $\boldsymbol{H}$, Quantitative analysis of dendritic Smo (number of Smo::tdTomato puncta per $10 \mu \mathrm{m}$ dendrite). $n=3$ for $\boldsymbol{E}, \boldsymbol{F}$, and $\boldsymbol{H}$. Error bars indicate SEM. ${ }^{* *} p<0.01,{ }^{*} p<0.05$, unpaired $t$ test. quences for Gli family transcription factor (Kinzler and Vogelstein, 1990), yet the protein abundance for all of them is significantly increased upon Shh stimulation (Hillman et al., 2011; Mitchell et al., 2012; this work). Although these two similarities are notable, the interaction between the Shh pathway and each of these three proteins is somewhat different. Although it does not contain the Gli target site, Bassoon has 11 potential binding sites for transcription factor $\mathrm{N}-m y c$, a target for Gli family transcription factors (Kenney et al., 2003; Oliver et al., 2003). This suggests an additional layer of regulation between Shh pathway activity and Bassoon expression levels. For Neuropilin1, it serves as a component of a positive regulatory loop for the Hh pathway: Hh pathway activity induces the expression of Neuropilin1, whereas knock-down of Neuropilin1 suppresses Shh pathway activity (Hillman et al., 2011). In the case of Pfn1, although it is not yet known how the Shh pathway regulates its abundance, overexpression of Pfn1 or Pfn1 actin-binding-deficient mutants do not seem to affect Shh pathway activity (P.J.Y., unpublished data). Furthermore, unlike neurons, Pf1 expression levels in 3T3 cells are not changed by Shh activity (Fig. 6H,I). Together, these findings indicate that elaborate and complex Shh pathway regulatory networks likely operate in neurons.

Among the Pfn isoforms, Pfn1 and Pfn2a are expressed in the mammalian brain (Witke, 2004; Birbach, 2008; Michaelsen et al., 2010). We find that both Pfn 1 and Pfn2a are expressed in young hippocampal neurons, but that only Pfn 1 protein expression level is upregulated by Shh pathway activity. Future experiments in which the ratio of the Pfn isoforms is altered by selective reduction or elimination will provide a better understanding of the regulation of $\mathrm{Pfn}$ in developing neurons.

Our data also indicate that the Shh pathway exerts an effect on another actin regulatory protein, the actin-filament-severing protein cofilin (Carlier et al., 1999). Although the level of serine 3-unphosphorylated cofilin is not affected by Shh activity, the serine 3-phosphorylated cofilin is markedly increased in Shh-treated neurons (Fig. 6). The serine 3-unphosphorylated cofilin is catalytically active, whereas phosphorylation at serine 3 makes it inactive (Arber et al., 1998; Yang et al., 1998). In addition, inhibiting actin assembly by treating neurons with latrunculin A prevented the Shh-induced extension of axons. Together, these findings support a model in which the Shhsignaling pathway promotes axon growth 
by regulating the expression and activity of actin filament modifiers in developing hippocampal neurons.

We found evidence for basal Shh pathway activity in the rat hippocampal culture system. In the absence of ShhN or SAG treatment, Shh pathway inhibitors (cyclopamine and GANT61) reduced axon growth and Pfn1 protein levels. The Glix8::EGFP transcriptional reporter also revealed low levels of pathway activity that are not detectable in untreated NIH $3 \mathrm{~T} 3$ cells (C.O., unpublished data). These results suggest that the Shh pathway could be important in regulating the timing and extent of axon growth in vivo. Intriguingly, using compartmentalized devices, we found that Shh signaling in the dendrites and soma triggers an anterograde sequence of events that extend axon length. We also found that Smo localization to dendrites increases upon Shh stimulation. In cilia-mediated signaling, Smo localization also changes when the pathway is activated. Perhaps localized Shh activates the pathway activity, alters Smo localization, triggers transcriptional changes (including upregulation of Pfn1), and results in axon extension. We propose a model in which, during hippocampal development, the axon of a neuron receiving Shh input to dendrites will undergo accelerated elongation, thereby reaching its target neurons sooner than neurons not receiving Shh input. Future in vivo experiments should provide important next steps in understanding the physiological relevance of Shh signaling in the development of hippocampal neurons.

\section{References}

Arber S, Barbayannis FA, Hanser H, Schneider C, Stanyon CA, Bernard O, Caroni P (1998) Regulation of actin dynamics through phosphorylation of cofilin by LIM-kinase. Nature 393:805-809. CrossRef Medline

Bakalyar HA, Reed RR (1990) Identification of a specialized adenylyl cyclase that may mediate odorant detection. Science 250:1403-1406. CrossRef Medline

Banker G, Goslin K (1988) Developments in neuronal cell culture. Nature 336:185-186. CrossRef Medline

Baudoin JP, Viou L, Launay PS, Luccardini C, Espeso Gil S, Kiyasova V, Irinopoulou T, Alvarez C, Rio JP, Boudier T, Lechaire JP, Kessaris N, Spassky N, Métin C (2012) Tangentially migrating neurons assemble a primary cilium that promotes their reorientation to the cortical plate. Neuron 76:1108-1122. CrossRef Medline

Beales P, Jackson PK (2012) Cilia-the prodigal organelle. Cilia 1:1. CrossRef Medline

Berbari NF, Bishop GA, Askwith CC, Lewis JS, Mykytyn K (2007) Hippocampal neurons possess primary cilia in culture. J Neurosci Res 85 : 1095-1100. CrossRef Medline

Beug ST, Parks RJ, McBride HM, Wallace VA (2011) Processing-dependent trafficking of Sonic hedgehog to the regulated secretory pathway in neurons. Mol Cell Neurosci 46:583-596. CrossRef Medline

Birbach A (2008) Profilin, a multi-modal regulator of neuronal plasticity. Bioessays 30:994-1002. CrossRef Medline

Breunig JJ, Sarkisian MR, Arellano JI, Morozov YM, Ayoub AE, Sojitra S, Wang B, Flavell RA, Rakic P, Town T (2008) Primary cilia regulate hippocampal neurogenesis by mediating sonic hedgehog signaling. Proc Natl Acad Sci U S A 105:13127-13132. CrossRef Medline

Briscoe J, Thérond PP (2013) The mechanisms of Hedgehog signalling and its roles in development and disease. Nat Rev Mol Cell Biol 14:416-429. Medline

Bushlin I, Petralia RS, Wu F, Harel A, Mughal MR, Mattson MP, Yao PJ (2008) Clathrin assembly protein AP180 and CALM differentially control axogenesis and dendrite outgrowth in embryonic hippocampal neurons. J Neurosci 28:10257-10271. CrossRef Medline

Carlier MF, Ressad F, Pantaloni D (1999) Control of actin dynamics in cell motility: role of ADF/cofilin. J Biol Chem 274:33827-33830. CrossRef Medline

Carlsson L, Nyström LE, Sundkvist I, Markey F, Lindberg U (1977) Actin polymerizability is influenced by profilin, a low molecular weight protein in non-muscle cells. J Mol Biol 115:465-483. CrossRef Medline

Caspary T, Larkins CE, Anderson KV (2007) The graded response to Sonic
Hedgehog depends on cilia architecture. Dev Cell 12:767-778. CrossRef Medline

Chen JK, Taipale J, Cooper MK, Beachy PA (2002a) Inhibition of Hedgehog signaling by direct binding of cyclopamine to Smoothened. Genes Dev 16:2743-2748. CrossRef Medline

Chen JK, Taipale J, Young KE, Maiti T, Beachy PA (2002b) Small molecule modulation of Smoothened activity. Proc Natl Acad Sci U S A 99:1407114076. CrossRef Medline

Cheng PL, Song AH, Wong YH, Wang S, Zhang X, Poo MM (2011) Selfamplifying autocrine actions of BDNF in axon development. Proc Natl Acad Sci U S A 108:18430-18435. CrossRef Medline

Chong YC, Mann RK, Zhao C, Kato M, Beachy PA (2015) Bifurcating action of Smoothened in Hedgehog signaling is mediated by Dlg5. Genes Dev 29:262-276. CrossRef Medline

Chou YH, Zheng X, Beachy PA, Luo L (2010) Patterning axon targeting of olfactory receptor neurons by coupled hedgehog signaling at two distinct steps. Cell 142:954-966. CrossRef Medline

Chu T, Chiu M, Zhang E, Kunes S (2006) A C-terminal motif targets Hedgehog to axons, coordinating assembly of the Drosophila eye and brain. Dev Cell 10:635-646. CrossRef Medline

Dahmane N, Ruiz i Altaba A (1999) Sonic hedgehog regulates the growth and patterning of the cerebellum. Development 126:3089-3100. Medline

De Luca A, Parmigiani E, Tosatto G, Martire S, Hoshino M, Buffo A, Leto K, Rossi F (2015) Exogenous sonic hedgehog modulates the pool of GABAergic interneurons during cerebellar development. Cerebellum 14: 72-85. CrossRef Medline

Fan CW, Chen B, Franco I, Lu J, Shi H, Wei S, Wang C, Wu X, Tang W, Roth MG, Williams NS, Hirsch E, Chen C, Lum L (2014) The Hedgehog pathway effector smoothened exhibits signaling competency in the absence of ciliary accumulation. Chem Biol 21:1680-1689. CrossRef Medline

Flynn KC, Hellal F, Neukirchen D, Jacob S, Tahirovic S, Dupraz S, Stern S, Garvalov BK, Gurniak C, Shaw AE, Meyn L, Wedlich-Söldner R, Bamburg JR, Small JV, Witke W, Bradke F (2012) ADF/cofilin-mediated actin retrograde flow directs neurite formation in the developing brain. Neuron 76:1091-1107. CrossRef Medline

Gonzalez-Reyes LE, Verbitsky M, Blesa J, Jackson-Lewis V, Paredes D, Tillack K, Phani S, Kramer ER, Przedborski S, Kottmann AH (2012) Sonic hedgehog maintains cellular and neurochemical homeostasis in the adult nigrostriatal circuit. Neuron 75:306-319. CrossRef Medline

Harwell CC, Parker PR, Gee SM, Okada A, McConnell SK, Kreitzer AC, Kriegstein AR (2012) Sonic hedgehog expression in corticofugal projection neurons directs cortical microcircuit formation. Neuron 73 : 1116-1126. CrossRef Medline

He Z, Tessier-Lavigne M (1997) Neuropilin is a receptor for the axonal chemorepellent Semaphorin III. Cell 90:739-751. CrossRef Medline

Hillman RT, Feng BY, Ni J, Woo WM, Milenkovic L, Hayden Gephart MG, Teruel MN, Oro AE, Chen JK, Scott MP (2011) Neuropilins are positive regulators of Hedgehog signal transduction. Genes Dev 25:2333-2346. CrossRef Medline

Huang Z, Kunes S (1996) Hedgehog, transmitted along retinal axons, triggers neurogenesis in the developing visual centers of the Drosophila brain. Cell 86:411-422. CrossRef Medline

Huangfu D, Liu A, Rakeman AS, Murcia NS, Niswander L, Anderson KV (2003) Hedgehog signalling in the mouse requires intraflagellar transport proteins. Nature 426:83-87. CrossRef Medline

Hyman JM, Firestone AJ, Heine VM, Zhao Y, Ocasio CA, Han K, Sun M, Rack PG, Sinha S, Wu JJ, Solow-Cordero DE, Jiang J, Rowitch DH, Chen JK (2009) Small-molecule inhibitors reveal multiple strategies for Hedgehog pathway blockade. Proc Natl Acad Sci U S A 106:14132-14137. CrossRef Medline

Ingham PW, McMahon AP (2001) Hedgehog signaling in animal development: paradigms and principles. Genes Dev 15:3059-3087. CrossRef Medline

Kaech S, Banker G (2006) Culturing hippocampal neurons. Nat Protoc 1:2406-2415. CrossRef Medline

Kenney AM, Cole MD, Rowitch DH (2003) Nmyc upregulation by sonic hedgehog signaling promotes proliferation in developing cerebellar granule neuron precursors. Development 130:15-28. CrossRef Medline

Kinzler KW, Vogelstein B (1990) The GLI gene encodes a nuclear protein which binds specific sequences in the human genome. Mol Cell Biol 10: 634-642. CrossRef Medline 
Kolodkin AL, Ginty DD (1997) Steering clear of semaphorins: neuropilins sound the retreat. Neuron 19:1159-1162. CrossRef Medline

Kunes S (2000) Axonal signals in the assembly of neural circuitry. Curr Opin Neurobiol 10:58-62. CrossRef Medline

Lanore F, Blanchet C, Fejtova A, Pinheiro P, Richter K, Balschun D, Gundelfinger E, Mulle C (2010) Impaired development of hippocampal mossy fibre synapses in mouse mutants for the presynaptic scaffold protein Bassoon. J Physiol 588:2133-2145. CrossRef Medline

Lauth M, Bergström A, Shimokawa T, Toftgård R (2007) Inhibition of GLImediated transcription and tumor cell growth by small-molecule antagonists. Proc Natl Acad Sci U S A 104:8455-8460. CrossRef Medline

Lewis PM, Gritli-Linde A, Smeyne R, Kottmann A, McMahon AP (2004) Sonic hedgehog signaling is required for expansion of granule neuron precursors and patterning of the mouse cerebellum. Dev Biol 270: 393-410. CrossRef Medline

Louvi A, Grove EA (2011) Cilia in the CNS: the quiet organelle claims center stage. Neuron 69:1046-1060. CrossRef Medline

Mattson MP, Murrain M, Guthrie PB, Kater SB (1989) Fibroblast growth factor and glutamate: opposing roles in the generation and degeneration of hippocampal neuroarchitecture. J Neurosci 9:3728-3740. Medline

Michaelsen K, Murk K, Zagrebelsky M, Dreznjak A, Jockusch BM, Rothkegel M, Korte M (2010) Fine-tuning of neuronal architecture requires two profilin isoforms. Proc Natl Acad Sci U S A 107:15780-15785. CrossRef Medline

Mitchell N, Petralia RS, Currier DG, Wang YX, Kim A, Mattson MP, Yao PJ (2012) Sonic hedgehog regulates presynaptic terminal size, ultrastructure and function in hippocampal neurons. J Cell Sci 125:4207-4213. CrossRef Medline

Okada A, Charron F, Morin S, Shin DS, Wong K, Fabre PJ, Tessier-Lavigne M, McConnell SK (2006) Boc is a receptor for sonic hedgehog in the guidance of commissural axons. Nature 444:369-373. CrossRef Medline

Oliver TG, Grasfeder LL, Carroll AL, Kaiser C, Gillingham CL, Lin SM, Wickramasinghe R, Scott MP, Wechsler-Reya RJ (2003) Transcriptional profiling of the Sonic hedgehog response: a critical role for N-myc in proliferation of neuronal precursors. Proc Natl Acad Sci U S A 100: 7331-7336. CrossRef Medline

Ott C, Lippincott-Schwartz J (2012) Visualization of live primary cilia dynamics using fluorescence microscopy. Curr Protoc Cell Biol Chapter 4:Unit 4.26. CrossRef Medline

Ott C, Elia N, Jeong SY, Insinna C, Sengupta P, Lippincott-Schwartz J (2012) Primary cilia utilize glycoprotein-dependent adhesion mechanisms to stabilize long-lasting cilia-cilia contacts. Cilia 1:3. CrossRef Medline

Park JW, Vahidi B, Taylor AM, Rhee SW, Jeon NL (2006) Microfluidic culture platform for neuroscience research. Nat Protoc 1:2128-2136. CrossRef Medline

Parra LM, Zou Y (2010) Sonic hedgehog induces response of commissural axons to Semaphorin repulsion during midline crossing. Nat Neurosci 13:29-35. CrossRef Medline

Persson L, Witt RM, Galligan M, Greer PL, Eisner A, Pazyra-Murphy MF, Datta SR, Segal RA (2014) Shh-proteoglycan interactions regulate maturation of olfactory glomerular circuitry. Dev Neurobiol 74:1255-1267. CrossRef Medline

Petralia RS, Wenthold RJ (1999) Immunocytochemistry of NMDA receptors. Methods Mol Biol 128:73-92. Medline

Petralia RS, Wang YX, Hua F, Yi Z, Zhou A, Ge L, Stephenson FA, Wenthold RJ (2010) Organization of NMDA receptors at extrasynaptic locations. Neuroscience 167:68-87. CrossRef Medline

Petralia RS, Schwartz CM, Wang YX, Mattson MP, Yao PJ (2011a) Subcellular localization of Patched and Smoothened, the receptors for Sonic hedgehog signaling, in the hippocampal neuron. J Comp Neurol 519: 3684-3699. CrossRef Medline

Petralia RS, Wang YX, Mattson MP, Yao PJ (2011b) Sonic hedgehog distribution within mature hippocampal neurons. Commun Integr Biol 4: 775-777. CrossRef Medline

Ressler KJ, Sullivan SL, Buck LB (1994) Information coding in the olfactory system: evidence for a stereotyped and highly organized epitope map in the olfactory bulb. Cell 79:1245-1255. CrossRef Medline

Salmon P, Trono D (2007) Production and titration of lentiviral vectors. Curr Protoc Hum Genet Chapter 12:Unit 12.10. CrossRef Medline

Sánchez-Camacho C, Bovolenta P (2008) Autonomous and non-autonomous Shh signalling mediate the in vivo growth and guidance of mouse retinal ganglion cell axons. Development 135:3531-3541. CrossRef Medline

Sasaki N, Kurisu J, Kengaku M (2010) Sonic hedgehog signaling regulates actin cytoskeleton via Tiam1-Rac1 cascade during spine formation. Mol Cell Neurosci 45:335-344. CrossRef Medline

Spassky N, Han YG, Aguilar A, Strehl L, Besse L, Laclef C, Ros MR, GarciaVerdugo JM, Alvarez-Buylla A (2008) Primary cilia are required for cerebellar development and Shh-dependent expansion of progenitor pool. Dev Biol 317:246-259. CrossRef Medline

Stanton BZ, Peng LF, Maloof N, Nakai K, Wang X, Duffner JL, Taveras KM, Hyman JM, Lee SW, Koehler AN, Chen JK, Fox JL, Mandinova A, Schreiber SL (2009) A small molecule that binds Hedgehog and blocks its signaling in human cells. Nat Chem Biol 5:154-156. CrossRef Medline

Suetsugu S, Miki H, Takenawa T (1998) The essential role of profilin in the assembly of actin for microspike formation. EMBO J 17:6516-6526. CrossRef Medline

Taipale J, Chen JK, Cooper MK, Wang B, Mann RK, Milenkovic L, Scott MP, Beachy PA (2000) Effects of oncogenic mutations in Smoothened and Patched can be reversed by cyclopamine. Nature 406:1005-1009. CrossRef Medline

Taylor AM, Blurton-Jones M, Rhee SW, Cribbs DH, Cotman CW, Jeon NL (2005) A microfluidicculture platform for CNS axonal injury, regeneration and transport. Nat Methods 2:599-605. CrossRef Medline

Taylor AM, Dieterich DC, Ito HT, Kim SA, Schuman EM (2010) Microfluidic local perfusion chambers for the visualization and manipulation of synapses. Neuron 66:57-68. CrossRef Medline

Traiffort E, Charytoniuk D, Watroba L, Faure H, Sales N, Ruat M (1999) Discrete localizations of hedgehog signalling components in the developing and adult rat nervous system. Eur J Neurosci 11:3199-3214. CrossRef Medline

Umetsu D, Murakami S, Sato M, Tabata T (2006) The highly ordered assembly of retinal axons and their synaptic partners is regulated by Hedgehog/Single-minded in the Drosophila visual system. Development 133:791-800. CrossRef Medline

Varjosalo M, Taipale J (2008) Hedgehog: functions and mechanisms. Genes Dev 22:2454-2472. CrossRef Medline

Vassar R, Chao SK, Sitcheran R, Nuñez JM, Vosshall LB, Axel R (1994) Topographic organization of sensory projections to the olfactory bulb. Cell 79:981-991. CrossRef Medline

Vosshall LB, Wong AM, Axel R (2000) An olfactory sensory map in the fly brain. Cell 102:147-159. CrossRef Medline

Wallace VA (1999) Purkinje-cell-derived Sonic hedgehog regulates granule neuron precursor cell proliferation in the developing mouse cerebellum. Curr Biol 9:445-448. Medline

Wechsler-Reya RJ, Scott MP (1999) Control of neuronal precursor proliferation in the cerebellum by Sonic Hedgehog. Neuron 22:103-114. CrossRef Medline

Wheatley DN, Wang AM, Strugnell GE (1996) Expression of primary cilia in mammalian cells. Cell Biol Int 20:73-81. CrossRef Medline

Willaredt MA, Tasouri E, Tucker KL (2013) Primary cilia and forebrain development. Mech Dev 130:373-380. CrossRef Medline

Wills Z, Marr L, Zinn K, Goodman CS, Van Vactor D (1999) Profilin and the Abl tyrosine kinase are required for motor axon outgrowth in the Drosophila embryo. Neuron 22:291-299. CrossRef Medline

Witke W (2004) The role of profilin complexes in cell motility and other cellular processes. Trends Cell Biol 14:461-469. CrossRef Medline

Wu CH, Fallini C, Ticozzi N, Keagle PJ, Sapp PC, Piotrowska K, Lowe P, Koppers M, McKenna-Yasek D, Baron DM, Kost JE, Gonzalez-Perez P, Fox AD, Adams J, Taroni F, Tiloca C, Leclerc AL, Chafe SC, Mangroo D, Moore MJ, et al. (2012) Mutations in the profilin 1 gene cause familial amyotrophic lateral sclerosis. Nature 488:499-503. CrossRef Medline

Yam PT, Charron F (2013) Signaling mechanisms of non-conventional axon guidance cues: the Shh, BMP and Wnt morphogens. Curr Opin Neurobiol 23:965-973. CrossRef Medline

Yamauchi K, Varadarajan SG, Li JE, Butler SJ (2013) Type Ib BMP receptors mediate the rate of commissural axon extension through inhibition of cofilin activity. Development 140:333-342. CrossRef Medline

Yang N, Higuchi O, Ohashi K, Nagata K, Wada A, Kangawa K, Nishida E, Mizuno K (1998) Cofilin phosphorylation by LIM-kinase 1 and its role in Rac-mediated actin reorganization. Nature 393:809-812. CrossRef Medline 